\title{
Phenotypic plasticity, QTL mapping and genomic characterization of bud set in black poplar
}

\author{
Francesco Fabbrini ${ }^{1}$, Muriel Gaudet ${ }^{1}$, Catherine Bastien², Giusi Zaina ${ }^{3}$, Antoine Harfouche ${ }^{1}$, Isacco Beritognolo ${ }^{1,4}$,
} Nicolas Marron ${ }^{1,5}$, Michele Morgante ${ }^{3,6}$, Giuseppe Scarascia-Mugnozza ${ }^{1,7}$ and Maurizio Sabatti ${ }^{*}$

\begin{abstract}
Background: The genetic control of important adaptive traits, such as bud set, is still poorly understood in most forest trees species. Poplar is an ideal model tree to study bud set because of its indeterminate shoot growth. Thus, a full-sib family derived from an intraspecific cross of P. nigra with 162 clonally replicated progeny was used to assess the phenotypic plasticity and genetic variation of bud set in two sites of contrasting environmental conditions.
\end{abstract}

Results: Six crucial phenological stages of bud set were scored. Night length appeared to be the most important signal triggering the onset of growth cessation. Nevertheless, the effect of other environmental factors, such as temperature, increased during the process. Moreover, a considerable role of genotype $\times$ environment $(G \times E)$ interaction was found in all phenological stages with the lowest temperature appearing to influence the sensitivity of the most plastic genotypes.

Descriptors of growth cessation and bud onset explained the largest part of phenotypic variation of the entire process. Quantitative trait loci (QTL) for these traits were detected. For the four selected traits (the onset of growth cessation (date2.5), the transition from shoot to bud (date1.5), the duration of bud formation (subproc1) and bud maturation (subproc2)) eight and sixteen QTL were mapped on the maternal and paternal map, respectively. The identified QTL, each one characterized by small or modest effect, highlighted the complex nature of traits involved in bud set process. Comparison between map location of QTL and P. trichocarpa genome sequence allowed the identification of 13 gene models, 67 bud set-related expressional and six functional candidate genes (CGs). These CGs are functionally related to relevant biological processes, environmental sensing, signaling, and cell growth and development. Some strong QTL had no obvious CGs, and hold great promise to identify unknown genes that affect bud set.

Conclusions: This study provides a better understanding of the physiological and genetic dissection of bud set in poplar. The putative QTL identified will be tested for associations in P. nigra natural populations. The identified QTL and CGs will also serve as useful targets for poplar breeding.

\section{Background}

Broad-leaved trees grown in temperate zones must avoid periods unfavorable for growth, such as harsh winter weather conditions, synchronizing their annual growth cycle with seasonality. Hence, they have evolved mechanisms to switch between active growth during summer and dormancy during winter, in response to environmental signals.

\footnotetext{
* Correspondence: sabatti@unitus.it

'Department for Innovation in Biological, Agro-food and Forest systems,

University of Tuscia, Via S. Camillo de Lellis, Viterbo 01100, Italy

Full list of author information is available at the end of the article
}

In trees and woody perennial plants, photoperiod (decrease of day length) typically induces growth cessation, the initiation of cold acclimation, the formation of a terminal bud (bud set) and bud dormancy [1]. Timing and duration of bud set process are inherited as quantitative traits, involving large number of genes with small individual effects [2-4]. Local adaptation of bud set phenology allows trees to find a compromise between the risk of frost damage and the maximization of the growing season duration [5]. In addition, bud activity determines the extent of the seasonal growth, tree architecture, wood quality and productivity [4]. 
Common garden studies have shown that timing of bud set is strongly correlated with latitude of origin of the population [5-9]. Trees from high latitudes are more sensitive to the photoperiod change than those from southern regions [10]. Even if day length is widely accepted to be the primarily used environmental signal, the timing of bud formation is also influenced by other factors, such as temperature [11], temperature $\times$ photoperiod ( $\times$ population) interaction [12-14], nutrition and drought $[4,15]$. It has also been demonstrated that bud set in Norway spruce (Picea abies) was strongly affected for many years by temperature during zygotic and somatic embryogenesis $[16,17]$, probably influenced by epigenetic memory [18]. This can be seen as a special form of phenotypic plasticity that opens the possibility of adaptation without genetic changes and, therefore, it is an important mechanism when adapting to climate changes [19]. Given the influence of temperature on tree phenology, growth cessation may be affected by climatic warming, which will increase the risk of frost damage in spring, and affect the survival and eventually the spatial distribution of forest trees, because of a less well-suited adaptation to the local altered environment [20]. Since range shift and changes in phenology are the best recorded shifts induced by climate change [19], phenological observations are very important for a better understanding of how different plant species respond to regional climate change [21,22]. Furthermore, research efforts are also required to investigate patterns of phenotypic plasticity, which can represent a crucial determinant of both short- and long-term plant responses [23].

Quantitative trait locus (QTL) mapping is a powerful approach to identify key genomic regions controlling adaptive traits $[3,24,25]$, especially for species where a reference genome is already available [26]. In the face of climate change, the main focus of QTL mapping studies in poplars has been on traits tightly linked to environmental adaptation, such as bud set and bud flush $[9,24,27,28]$. In Populus nigra (black poplar) the genes underlying these adaptive traits remain largely unknown, but genetic maps with hundreds of molecular markers are available [29]. These genetic maps, expanded with gene-specific single nucleotide polymorphisms (SNPs), provide a foundation for the investigation of the genomic regions underlying adaptive traits.

Therefore, the objectives of this study were (i) to assess phenotypic plasticity and evaluate the relative importance of genotype $\times$ environment $(G \times E)$ interaction in the phenotypic expression (or variation) of bud set in P. nigra through a multi-environment approach, (ii) to identify genomic regions underlying the bud set process through QTL mapping and (iii) to select a set of promising candidate genes (CGs) in highlighted genomic regions.

\section{Results}

\section{Dynamics of bud set process in the two sites}

The parent '58-861' was the earliest genotype to reach the onset of growth cessation (date2.5) in Viterbo (VT), but it attained this stage beforehand in Cavallermaggiore (CV). In addition, transgressive segregation of some offspring over the earliest '58-861' parent was observed at both field sites (Figure 1a,b,c). However, the parent 'Poli' was the latest genotype to reach all stages of the bud set process. Because 'Poli' is not well-enough adapted to the climate conditions of the CV northern experimental site, it did not survive after re-sprouting. Therefore, significant differences between the two parents for all the onset-of-stage traits could only be detected at VT. Moreover, the two sites did not show clear differences in photoperiod regime during the period of bud set measurements (Additional file 1: Figure S1). Cumulative minimum temperature (CMT) between July and October demonstrated that CV was a colder site on average (Figure 2a). However, when higher weights are given to minimum temperature $<10^{\circ} \mathrm{C}\left(\mathrm{CMT}_{10}\right)$, the observed cumulative minimum temperature pattern provided additional description of a temporary but early fall of temperature at VT.

The average timing of date 2.5 at population level was similar at the two sites, i.e. day of the year (DOY) 267 amounting to about 864 and 862 h of cumulative night length (CNL) in $\mathrm{CV}$ and VT, respectively, with only three minutes difference in terms of effective night length between the two sites (Table 1). The same population mean was also found at both sites for date0.5, i.e. DOY 286 (corresponding to a minor difference in terms of CNL), for a total of $18.8 \mathrm{~d}$ needed on average by the full-sib family studied (POP5) to cover the whole phenological process (Table 1). Actually, the high value of Pearson correlations among the five phenological stages showed that, when the growth cessation process begins, all the onset-of-stage traits follow constantly through a cascade process (Table $2 \mathrm{a}, \mathrm{b})$. While the population mean of the most distant phenological stages was the same at both sites, a great variation at genotypic level could be observed. Early bud set genotypes reached date2.5 at DOY 262.9 in VT and at DOY 259 in CV, with about four days differences between sites.

As for bud set subprocesses at the two sites, the duration of bud maturation (subproc2, $10.6 \mathrm{~d}$ in $\mathrm{CV}$ and $11.6 \mathrm{~d}$ in VT) was longer than the duration of bud formation (subproc1, $8.2 \mathrm{~d}$ in $\mathrm{CV}$ and $7.3 \mathrm{~d}$ in VT). Consequently, subproc2 experienced longer CNL and higher $\mathrm{CMT}_{10}$ than subproc1 (Figure $1 \mathrm{~d}$ and $2 \mathrm{~b}$ ). 
(a)

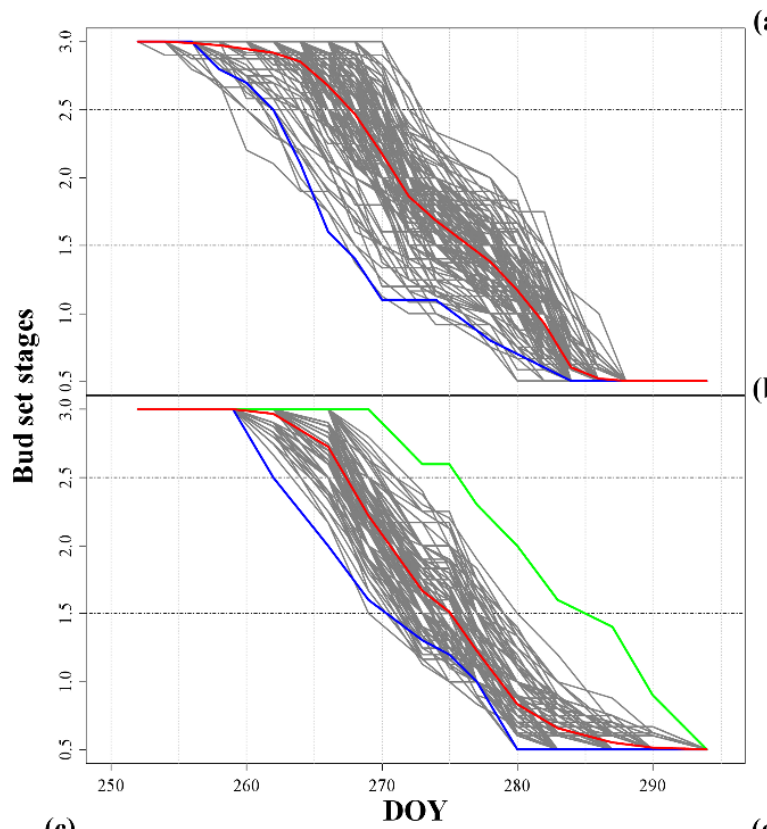

(d)

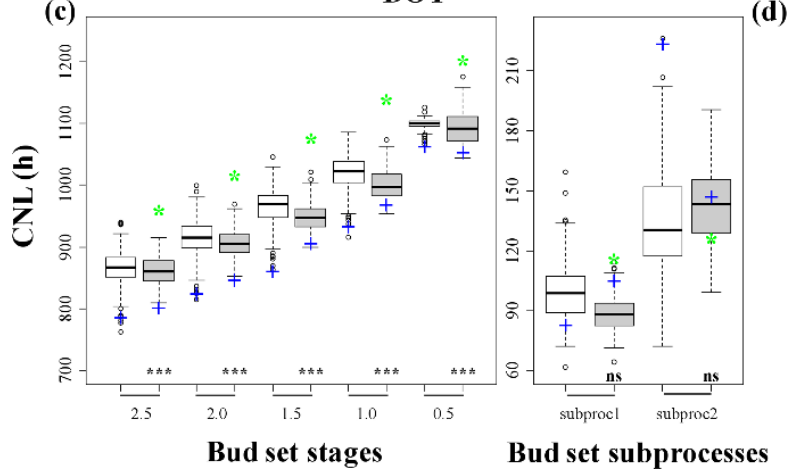

Figure 1 Phenotypic variation of bud set in a Populus nigra full-sib family (POP5). POP5 grown in two experimental sites in Italy: Cavallermaggiore (CV) and Viterbo (VT). Genotype means for the progenies in CV (a) and VT (b) are plotted in grey lines. Full-sib family mean is indicated by red lines, the female parent '58-861' by blue lines and the male parent 'Poli' by a green line. Horizontal dashed lines indicate the two critical points of bud set process, which correspond to the onset of growth cessation (date2.5) and the transition from shoot to bud (date1.5). (c) Phenotypic variation for all phenological stages, and (d) subprocesses observed in CV (white boxes) and VT (grey boxes) using block-adjusted genotype means expressed as cumulative night length (CNL). The parent '58861 ' is indicated by blue " + ", and the parent 'Poli' by green "*". The significance level of differences between the two parents for each trait is indicated as: $n s$, non-significant; ${ }^{*}, P \leq 0.05 ;{ }^{*}, P \leq 0.01 ;{ }^{* * *}, P$ $\leq 0.001$.

Moreover, subproc2 was negatively correlated with date2.5 especially at the northern site $(r=-0.84)$ (Table 2a).

In VT, phenological patterns of the two parents did not show significant differences in subprocesses relating to CNL (Figure 1d). With regards to $\mathrm{CMT}_{10}$, differences were exhibited only in subproc2 (Figure $2 \mathrm{~b}$ ). The parent
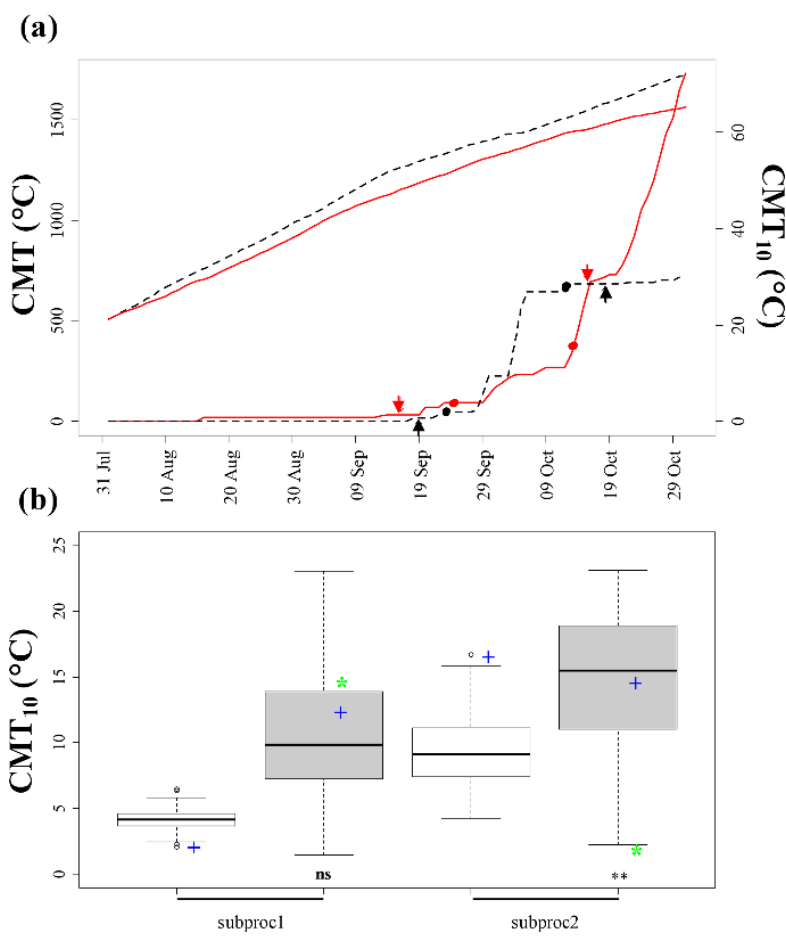

Bud set subprocesses

Figure 2 Temperature and duration of bud set process. Data were observed in two sites in Italy: Cavallermaggiore (CV) and Viterbo (VT). (a) Cumulative minimum temperature (CMT) and CMT $<10^{\circ} \mathrm{C}\left(\mathrm{CMT}_{10}\right)$ were calculated from July $1^{\text {st }}$ for $\mathrm{CV}$ (red full lines) and VT (black dotted lines). Arrows indicate the two extreme genotypes for bud set stages (date2.5 and date0.5) in CV (red) and VT (black). Dots indicate population mean in CV (red) and VT (black) for the same stages. The upper lines refer to CMT, whereas the bottom lines refer to $\mathrm{CMT}_{10}$. (b) Phenotypic variation of subproc1 and subproc2 observed in CV (white boxes) and VT (grey boxes). The parent ' $58-861$ ' is indicated by blue " + ", and the parent 'Poli' by green "*". The significance level of differences between the two parents for each trait is indicated as: $n s$, non-significant; ${ }^{*}, P \leq 0.05$; ${ }^{* *}, P \leq 0.01 ;{ }^{* *}, P \leq 0.001$.

'58-861' was one of the fastest genotypes to complete subproc1 in CV but, on the contrary, it was very slow to complete subproc2. However, in VT, the two parents did not show extreme values in the family distribution and scored similar subprocesses in terms of CNL (Figure 1d). For the parent 'Poli', subproc1 and subproc2 showed similar duration relating to CNL in VT (Figure $1 d$ ), but it experienced cold temperature only in subproc1 (Figure $2 \mathrm{~b}$ ). The parent '58-861' required more time to complete subproc1 and less time to complete subproc2 in VT than in CV (Figure 1d). Differences in subproc1 dependent on $\mathrm{CMT}_{10}$ were observed between the two sites (Figure 2b). Linear regressions between selected phenological characters, according to principal component analysis (PCA), and biometric traits demonstrated that in our experiments growth characters did 
Table 1 Timing and duration of bud set process in a Populus nigra full-sib family (POP5).

\begin{tabular}{|c|c|c|c|c|c|c|c|c|c|c|c|c|c|c|c|}
\hline \multirow{3}{*}{ Site } & \multicolumn{9}{|c|}{ Population mean } & \multicolumn{6}{|c|}{ Genotype mean } \\
\hline & \multicolumn{3}{|c|}{ date2.5 } & \multicolumn{3}{|c|}{ date 0.5} & \multicolumn{3}{|c|}{ Total duration of process } & \multicolumn{3}{|c|}{ Earliest for date2.5 } & \multicolumn{3}{|c|}{ Latest for date 0.5} \\
\hline & DOY & CNL (h) & $\mathrm{CMT}_{10}\left({ }^{\circ} \mathrm{C}\right)$ & DOY & CNL & $\mathrm{CMT}_{10}$ & DOY & CNL & $\mathrm{CMT}_{10}$ & DOY & CNL & $\mathrm{CMT}_{10}$ & DOY & CNL & $\mathrm{CMT}_{10}$ \\
\hline$\overline{\mathrm{CV}}$ & 267.65 & 864.23 & 3.70 & 286.45 & 1098.25 & 17.29 & 18.80 & 234.02 & 13.59 & 259.03 & 762.21 & 1.49 & 288.54 & 1125.65 & 22.57 \\
\hline VT & 267.32 & 861.95 & 2.76 & 286.17 & 1093.54 & 27.82 & 18.85 & 231.59 & 25.06 & 262.87 & 809.51 & 0.46 & 292.29 & 1175.05 & 28.51 \\
\hline
\end{tabular}

POP5 grown in two experimental sites in Italy: Cavallermaggiore (CV) and Viterbo (VT). Values are expressed as day of the year (DOY), cumulative night length $(\mathrm{CNL})$ and cumulative minimum temperature $<10^{\circ} \mathrm{C}\left(\mathrm{CMT}_{10}\right)$ for date2.5, date 0.5 and the total process length at population level. The genotype means of date2.5 for the earliest genotype and of date 0.5 for the latest one, expressed using all the parameters considered, are shown.

not influence the phenotypic variation of bud set (Additional file 2: Figure S2).

\section{Broad-sense heritability of bud set traits}

Substantial within-site genetic variation for all traits is presented in Additional file 3: Table S1 and Additional file 4: Table S2. In general, data showed higher levels of phenotypic variance and lower broad-sense heritability $\left(\mathrm{H}^{2}\right)$ for duration traits as compared to onset-of-stage traits (Table 3). Phenological bud set traits expressed as CNL showed a decreasing trend in terms of genetic component of variance from date 2.5 to date 0.5 at both sites, with broad-sense heritability at genotypic level $\left(\mathrm{H}_{\text {gen }}{ }^{2}\right)$ ranging from 0.84 to 0.43 in $\mathrm{CV}$, and from 0.74 to 0.45 in VT (Table 3). The transition from shoot to bud structure (i.e. date1.5) showed quite similar $\mathrm{H}_{\text {gen }}{ }^{2}$ values between the two sites $\left(0.73<\mathrm{H}_{\text {gen }}{ }^{2}<0.75\right)$. Duration traits and subprocesses, analysed using the CNL parameter, showed low levels of $\mathrm{H}^{2}$ especially at individual level $\left(\mathrm{H}_{\text {ind }}{ }^{2}\right)$ in VT $\left(0.03<\mathrm{H}_{\text {ind }}{ }^{2}<0.09\right)$ (Additional file 4: Table S2).
We observed a positive genetic correlation among onset-of-stage traits. Additionally, subproc 2 was negatively correlated with date $2.5\left(r_{\mathrm{g}}=-0.92 \pm 0.01\right.$ in $\mathrm{CV}$ and $r_{g}=-0.56 \pm 0.06$ in VT). Both these cases were also previously shown by linear correlations at the two sites (Table 2a,b).

\section{$\mathrm{G} \times \mathrm{E}$ interaction and phenotypic plasticity}

Genotype $\times$ environment $(G \times E)$ interaction was calculated using a two-way analysis of variance with environment (including both site and year) and genotype as variation factors. The sources of phenotypic variation (genotype, $\mathrm{G} \times \mathrm{E}$ ) were statistically significant with no environment effect in date2.5. Likewise, there was no G $\times E$ interaction effect on duration2.5 (Table 3). The relative importance of the genotypic effect as well as the G $\times$ E component were considerable in all the onset-ofstage traits with a decreasing trend from date 2.5 to date 0.5 . The phenotypic variation explained by the genotype component ranged from $29.6 \%$ (date2.5) to $5.8 \%$

Table 2 Correlations between bud set traits in a Populus nigra full-sib family (POP5).

\begin{tabular}{|c|c|c|c|c|c|c|c|c|c|c|c|c|c|c|}
\hline & (a) & & & & & & & (b) & & & & & & \\
\hline & date2.5 & date2 & date1.5 & date1 & date 0.5 & subproc1 & subproc2 & date 2.5 & date2 & date1.5 & date1 & date 0.5 & subproc1 & subproc2 \\
\hline \multirow[t]{2}{*}{ date2.5 } & & 0.97 & 0.89 & 0.81 & 0.62 & & -0.84 & & 0.98 & 0.93 & 0.83 & 0.63 & & -0.24 \\
\hline & & $* * *$ & $* * *$ & **** & $* * *$ & & $* * *$ & & $* * *$ & $* * *$ & $* * *$ & **** & & $* *$ \\
\hline \multirow[t]{2}{*}{ date2 } & 0.99 & & 0.96 & 0.89 & 0.61 & & -0.92 & 0.99 & & 0.98 & 0.90 & 0.69 & & -0.20 \\
\hline & 0.00 & & $* * *$ & $* * *$ & $* * *$ & & $* * *$ & 0.00 & & **** & $* * *$ & $* * *$ & & * \\
\hline \multirow[t]{2}{*}{ date1.5 } & 0.93 & 0.97 & & 0.97 & 0.63 & 0.24 & -0.96 & 0.98 & 1.00 & & 0.96 & 0.76 & 0.36 & -0.12 \\
\hline & 0.01 & 0.00 & & $* * *$ & $* * *$ & $* *$ & $* * *$ & 0.00 & 0.00 & & $* * *$ & $* * *$ & $* * *$ & ns \\
\hline \multirow[t]{2}{*}{ date1 } & 0.87 & 0.93 & 0.98 & & 0.68 & 0.33 & & 0.96 & 0.99 & 1.00 & & 0.88 & 0.50 & \\
\hline & 0.02 & 0.01 & 0.00 & & $* * *$ & $* * *$ & & 0.01 & 0.00 & 0.00 & & $* * *$ & $* * *$ & \\
\hline \multirow[t]{2}{*}{ date0.5 } & 0.78 & 0.72 & 0.58 & 0.84 & & 0.03 & & 0.88 & 0.93 & 0.96 & 0.98 & & 0.49 & \\
\hline & 0.03 & 0.04 & 0.05 & 0.02 & & ns & & 0.02 & 0.01 & 0.01 & 0.00 & & $* * *$ & \\
\hline \multirow[t]{2}{*}{ subproc1 } & & & -0.08 & -0.17 & 0.11 & & -0.27 & & & -0.31 & -0.42 & -0.59 & & 0.28 \\
\hline & & & 0.08 & 0.08 & 0.08 & & $* * *$ & & & 0.07 & 0.07 & 0.05 & & $* * *$ \\
\hline \multirow[t]{2}{*}{ subproc2 } & -0.92 & -0.98 & -1.00 & & & 0.08 & & -0.56 & -0.47 & -0.37 & & & 0.74 & \\
\hline & 0.01 & 0.00 & 0.01 & & & 0.08 & & 0.06 & 0.06 & 0.07 & & & 0.04 & \\
\hline
\end{tabular}

POP5 grown in two experimental sites in Italy: Cavallermaggiore (CV) and Viterbo (VT). Data were analyzed on cumulative night length (CNL) basis. (a) Within site phenotypic (above the diagonal) and genetic (below the diagonal, with \pm standard deviation (SD)) correlations for CV and (b) likewise for VT. The levels of significance of the Pearson coefficient are indicated as: $n s$, non-significant; ${ }^{*}, P \leq 0.05 ;{ }^{*}, P \leq 0.01 ;{ }^{* * *}, P \leq 0.001$. 
Table 3 Variance components and genotype ranking for stages and duration traits of bud set process.

\begin{tabular}{|c|c|c|c|c|c|c|c|c|c|c|c|}
\hline \multirow{3}{*}{$\begin{array}{r}\text { CNL } \\
\text { date2.5 }\end{array}$} & \multicolumn{7}{|c|}{ Variance components (\%) } & \multicolumn{2}{|c|}{ Broad-sense heritability } & \multirow{2}{*}{\multicolumn{2}{|c|}{$\frac{\text { Spearman Rank }}{\rho}$}} \\
\hline & \multicolumn{2}{|c|}{$\sigma_{E}^{2} / \sigma_{P}^{2}$} & \multicolumn{2}{|c|}{$\sigma_{G}^{2} / \sigma_{P}^{2}$} & \multicolumn{2}{|c|}{$\sigma_{G \times E}^{2} / \sigma_{P}^{2}$} & \multirow{2}{*}{$\frac{\sigma_{\varepsilon}^{2} / \sigma_{P}^{2}}{51.4}$} & \multirow{2}{*}{$\frac{\mathbf{H}_{\text {gen }}^{\mathbf{C}} \mathbf{C V}}{0.84}$} & \multirow{2}{*}{$\frac{\mathbf{H}_{\text {gen }}^{\mathbf{2}} \mathbf{V T}}{0.73}$} & & \\
\hline & 0.0 & $n s$ & 29.6 & **** & 19.0 & *** & & & & 0.51 & **** \\
\hline date2 & 1.1 & $* * *$ & 27.1 & $* * *$ & 18.8 & $* * *$ & 53.0 & 0.81 & 0.74 & 0.51 & $* * *$ \\
\hline date 1.5 & 5.6 & $* * *$ & 21.8 & $* * *$ & 16.8 & $* * *$ & 55.8 & 0.75 & 0.73 & 0.46 & $* * *$ \\
\hline date1 & 9.7 & $* * *$ & 17.2 & $* * *$ & 13.1 & $* * *$ & 60.0 & 0.70 & 0.64 & 0.39 & $* * *$ \\
\hline date0.5 & 2.9 & $* * *$ & 5.8 & $* * *$ & 9.2 & $* * *$ & 82.1 & 0.43 & 0.45 & 0.22 & $* *$ \\
\hline duration 2.5 & 3.2 & $* * *$ & 8.9 & $* * *$ & 0.0 & ns & 87.9 & 0.36 & 0.28 & 0.27 & ** \\
\hline duration2 & 14.5 & $* * *$ & 2.9 & $* * *$ & 7.7 & $* *$ & 74.8 & 0.49 & 0.24 & 0.09 & ns \\
\hline duration 1.5 & 6.3 & $* * *$ & 0.9 & $* * *$ & 11.5 & $* * *$ & 81.3 & 0.57 & 0.15 & 0.06 & ns \\
\hline duration1 & 12.4 & $* * *$ & 1.9 & $* * *$ & 16.3 & $* * *$ & 69.4 & 0.62 & 0.10 & 0.08 & ns \\
\hline subproc1 & 11.3 & $* * *$ & 5.3 & $* * *$ & 4.9 & * & 78.4 & 0.44 & 0.27 & 0.18 & * \\
\hline subproc2 & 3.1 & $* * *$ & 0.8 & $* * *$ & 20.0 & $* * *$ & 76.1 & 0.67 & 0.15 & 0.01 & ns \\
\hline
\end{tabular}

Data were obtained from a Populus nigra full-sib family (POP5) grown in two sites in Italy: Cavallermaggiore (CV) and Viterbo (VT). Data were analyzed on cumulative night length $(\mathrm{CNL})$ basis. Relative importance of environment $\left(\sigma_{\mathrm{E}}^{2}\right)$, genotype $\left(\sigma^{2}{ }_{G}\right)$, genotype by environment $\left(\sigma_{\mathrm{GXE}}^{2}\right)$ and residual $\left(\sigma^{2}\right)$ effects on the phenotypic variation $\left(\sigma_{P}^{2}\right)$ are presented together with values of broad-sense heritability at genotypic level ( $\mathrm{H}^{2}$ gen). Spearman rank coefficients $(\rho)$ were calculated from genotype means in CV and VT. The significance level of differences between the two parents for each trait is indicated as: $\mathrm{ns}, \mathrm{non}-\mathrm{significant;}^{*}, P \leq 0.05 ;{ }^{* *}$ $P \leq 0.01 ; * *, P \leq 0.001$.

(date0.5) and from 19.0\% (date2.5) to 9.2\% (date0.5) for the $\mathrm{G} \times \mathrm{E}$ interaction.

Spearman rank coefficients were positive, moderate and highly significant for the onset-of-stage traits, but they decreased during time. Hence, there were not significant changes in the ranking of genotypes between environments, but the degree of changes increased gradually during time (Table 3). Concerning duration traits, low levels of genotypic variance $\left(0.8 \%<{\sigma_{\mathrm{G}}}^{2} / \sigma_{\mathrm{P}}{ }^{2}<8.9 \%\right)$ and high levels of residuals (up to $87.9 \%$ ) in the phenotypic variation were observed, with an increasing importance of the $\mathrm{G} \times \mathrm{E}$ interaction during bud development (from $0 \%$ to $20 \%$ ). The low values of Spearman coefficients for duration traits were a clear indication of strong and random changes in genotype ranking between environments (Table 3 ).

The interaction pattern of the population mean for date2.5 expressed as DOY, indicative of the critical day length inducing growth cessation, showed an almost horizontal trend for the three studied sites. Parent '58861' was a very plastic genotype showing an earlier onset of growth cessation in Savigliano (SAV) and CV as compared to VT. The onset of growth cessation was initiated at different night lengths at the three sites, with a difference of about $20 \mathrm{~min}$ between SAV and VT. $\mathrm{CMT}_{10}$ in SAV, CV and VT $\left(4.8^{\circ} \mathrm{C}, 1.7^{\circ} \mathrm{C}\right.$ and $0.45^{\circ} \mathrm{C}$, respectively) contributed to the delay of growth cessation of this genotype (Figure 3). Conversely, 'Poli' appeared to be less plastic for date 2.5 and its response seemed mainly influenced by the photoperiod. It reached date2.5 at a similar effective night length, with a difference of 5 min between SAV and VT, showing a minor sensitivity to increasing value of $\mathrm{CMT}_{10}$ (Figure $3)$.

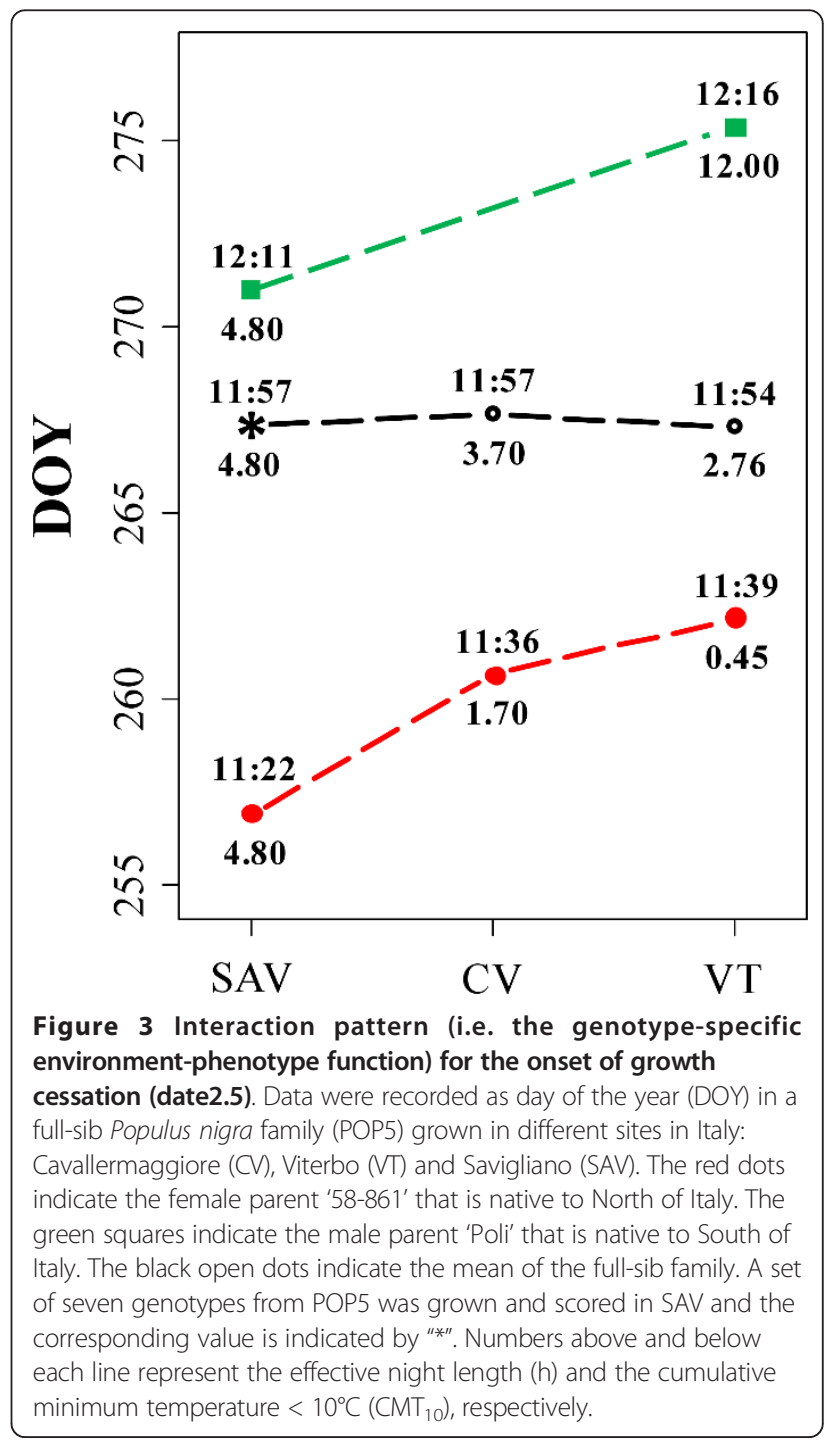


The relative ecovalence analysis (Figure 4a) showed only a few genotypes contributing to the overall $\mathrm{G} \times \mathrm{E}$ interaction. These genotypes were the most extreme genotypes in CV for date 2.5 (Figure 4b,c). Seventeen of the most plastic genotypes contributed for $50 \%$ of the $\mathrm{G}$ $\times E$ interaction. Thirteen of them demonstrated an interaction pattern describing a positive slope CV-VT in relation to $\mathrm{CMT}_{10}$. The remaining four genotypes, which were the latest in $\mathrm{CV}$, had a negative slope that was probably due to non controlled factors (e.g. site quality and nutrients availability) (Figure $4 \mathrm{~b}$ ). The duration of the bud set process of the thirteen plastic genotypes with early date 2.5 in CV was always shorter in VT than in CV. Moreover, these genotypes always initiated date2.5 later in VT than in $\mathrm{CV}$, where $\mathrm{CMT}_{10}$ was reached earlier (Figure 2a and Figure 4c).

\section{QTL analyses}

Discriminative bud set traits for QTL analysis were a list of complementary traits, which explain together a large part (\% from PCA on this list of traits) of phenotypic variation observed for growth cessation and bud onset. The trait date2.5, although highly correlated with date1.5, was added because we consider it physiologically remarkable (perception of critical day length) and scarcely reported in literature. For these four traits eight and 16 QTL were mapped on the maternal and paternal map, respectively. Genetic parameters for the detected
QTL are shown in Table 4. The QTL intervals were located on 12 linkage groups (LG): I, III, IV, VI, VII, X, XI, XIII, XVI, XVII, XVIII and XIX (Figure 5). QTL for date1.5 and date2.5 co-localized on LG-IV, X, XVI, XVII, and on LG-Ia together with subproc2. On LGVIb, QTL intervals for subproc1, subproc2 and date1.5 overlapped (Figure 5). The average percentage of variance explained (PVE) by individual QTL was 5.5\%, and the maximum PVE per trait was $40.1 \%$ (Table 5). Three QTL, two for subproc1 and one for subproc2, had effects with opposite directions between the two sites (Table 4), thus reflecting the negative genetic correlation between these traits and the onset-of-stage traits (Table $2 a, b)$. Seven of the 16 QTL for the paternal map and one of the eight QTL for the maternal map had significant differences between the two sites (Table 4).

\section{Identification of CGs}

Anchored simple sequence repeat (SSR) markers have allowed linking 19 out of 24 identified QTL to the physical map. Genomic intervals of QTL on LG-I, IV, X, XIII, XVI and XVII, corresponding to co-locating QTL with high PVE, were analyzed. Their intervals ranged from 1.7 to $10.6 \mathrm{Mbp}$, considering a unique overlapping region where QTL co-localized. The number of gene models in these intervals ranged from 125 to 990 . The total number of gene models in all the intervals was 3317 (Table 6). The availability of the genome sequence
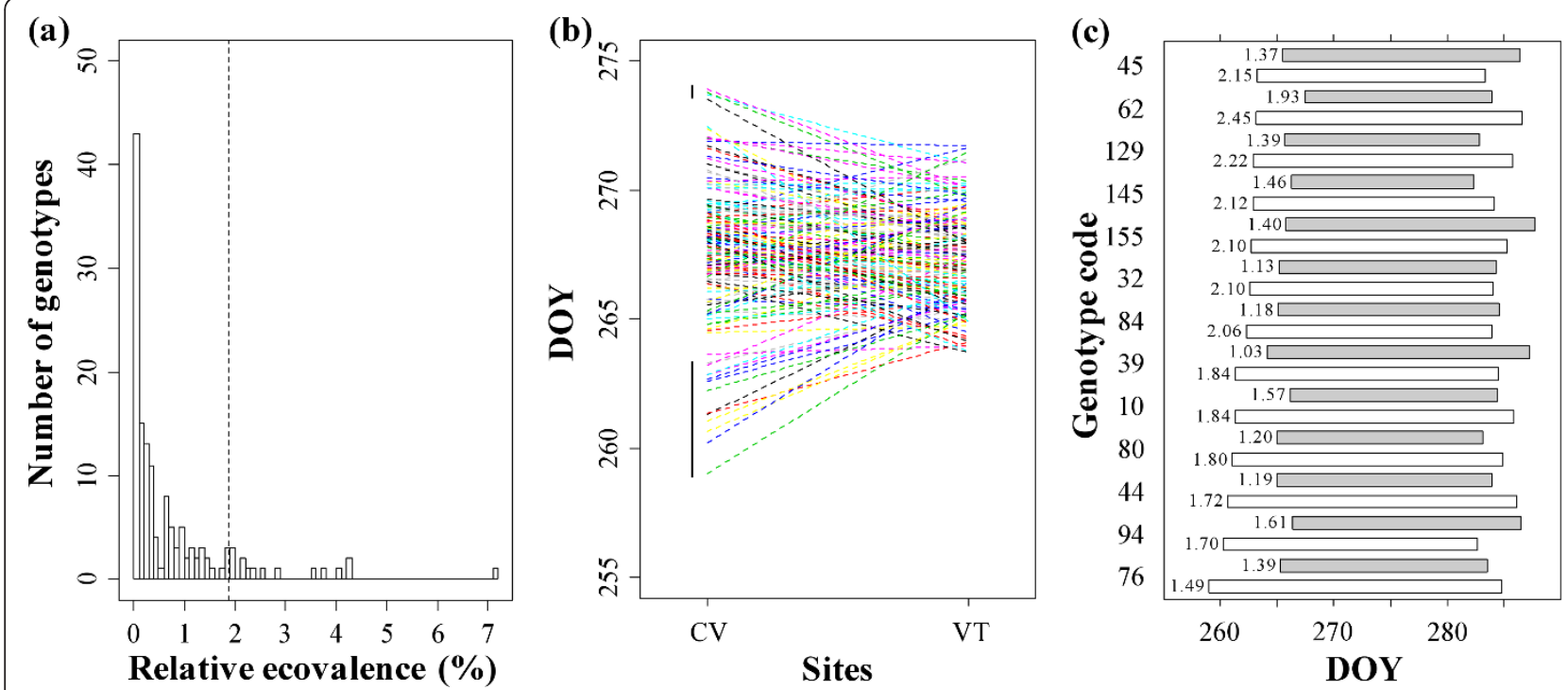

Figure 4 Analysis of phenotypic plasticity of bud set in a Populus nigra full-sib family (POP5). Data were observed in two sites in Italy: Cavallermaggiore (CV) and Viterbo (VT). (a) Frequency distribution of the genotype relative ecovalence (\%). The vertical dotted line separates the 17 most plastic genotypes, accounting $50 \%$ of the total $\mathrm{G} \times \mathrm{E}$ observed for the onset of growth cessation (date2.5). (b) Interaction patterns of the full-sib genotypes. The vertical black lines indicate the 17 most plastic genotypes. (c) Total duration of bud set process for 13 of these plastic genotypes that showed an interaction pattern with a positive slope $\mathrm{CV}-\mathrm{VT}$ in terms of cumulative minimum temperature $<10^{\circ} \mathrm{C}(\mathrm{CMT} 10)$. Bars represent the duration from onset of growth cessation (date2.5) to the end of bud maturation (date0.5), measured in day of the year (DOY) in CV (white bars) and VT (grey bars). The $\mathrm{CMT}_{10}$ value corresponding to date2.5 is reported on the left of each bar. 
Table 4 Identified quantitative trait loci (QTL) for bud set.

\begin{tabular}{|c|c|c|c|c|c|c|c|c|c|}
\hline \multirow{2}{*}{$\begin{array}{l}\text { Parental } \\
\text { map }\end{array}$} & \multirow[t]{2}{*}{ Trait } & \multirow[t]{2}{*}{ LG } & \multirow[t]{2}{*}{ LOD } & \multirow[t]{2}{*}{$95 \% \mathrm{Cl}$} & \multicolumn{2}{|c|}{ Genetic effect } & \multirow[t]{2}{*}{$P$-value } & \multicolumn{2}{|l|}{ PVE } \\
\hline & & & & & $\mathrm{CV}$ & VT & & $\overline{C V}$ & VT \\
\hline Poli & date2.5 & la & 3.46 & {$[3.2-39.1]$} & -21.576 & -2.912 & $* * *$ & 0.119 & 0.004 \\
\hline Poli & date1.5 & la & 3.31 & {$[7.9-39.4]$} & -19.869 & -3.091 & $* *$ & 0.099 & 0.004 \\
\hline Poli & subproc2 & la & 3.24 & [16.98-39.4] & 19.448 & -0.894 & * & $\underline{0.126}$ & 0.001 \\
\hline Poli & date1.5 & $\mathrm{lb}$ & 3.14 & [46.4-109] & -12.802 & -8.896 & & 0.041 & 0.036 \\
\hline Poli & subproc1 & IC & 3.58 & [30.4-101.1] & -9.750 & -1.187 & * & 0.099 & 0.005 \\
\hline Poli & date2.5 & $\mathrm{IVb}$ & 4.15 & [13.8-105.9] & 13.455 & 11.056 & & 0.046 & 0.064 \\
\hline Poli & date1.5 & $\mathrm{IVb}$ & 4.64 & {$[0-78]$} & 19.031 & 11.489 & & 0.091 & 0.059 \\
\hline Poli & subproc1 & Vla & 2.50 & [51.4-131.6] & -2.462 & 4.706 & * & 0.006 & 0.072 \\
\hline Poli & date1.5 & $\mathrm{Vlb}$ & 4.50 & [3.4-21.8] & -22.109 & -1.114 & $* * *$ & $\underline{0.126}$ & 0.001 \\
\hline Poli & subproc1 & $\mathrm{Vlb}$ & 2.91 & [12.1-21.8] & -8.473 & -1.438 & & 0.075 & 0.007 \\
\hline Poli & subproc2 & $\mathrm{Vlb}$ & 2.59 & {$[0-21.8]$} & 17.730 & 1.219 & * & 0.104 & 0.001 \\
\hline Poli & date2.5 & $X I$ & 2.94 & [15.7-129.5] & -13.841 & -9.081 & & 0.049 & 0.043 \\
\hline Poli & date2.5 & XIII & 4.81 & [72.8-92.9] & 16.009 & 9.950 & & 0.065 & 0.051 \\
\hline Poli & date2.5 & $\mathrm{XVII}$ & 3.30 & [71.3-152.1] & 10.145 & 12.910 & & 0.026 & 0.085 \\
\hline Poli & date1.5 & $\mathrm{XVII}$ & 4.11 & [79.8-132.6] & 13.047 & 15.258 & & 0.044 & $\underline{0.105}$ \\
\hline Poli & subproc1 & XIXa & 2.32 & [15.8-69.4] & -5.019 & -4.323 & & 0.026 & 0.061 \\
\hline $58-861$ & date2.5 & III & 3.40 & [0-97.1] & 3.761 & 13.106 & & 0.003 & 0.085 \\
\hline $58-861$ & subproc1 & VII & 2.77 & [27.3-57.7] & -0.107 & 5.385 & & 0.000 & 0.093 \\
\hline $58-861$ & date2.5 & $x$ & 5.80 & {$[0-25]$} & 16.742 & 14.312 & & 0.065 & 0.102 \\
\hline $58-861$ & date1.5 & $x$ & 4.95 & {$[0-47.4]$} & 12.925 & 16.204 & & 0.038 & 0.113 \\
\hline $58-861$ & subproc1 & XIII & 2.49 & {$[0.2-121.1]$} & 10.093 & 0.839 & * & 0.107 & 0.002 \\
\hline $58-861$ & date2.5 & $\mathrm{XVI}$ & 3.85 & {$[4.2-58.6]$} & 18.767 & 8.545 & & 0.081 & 0.036 \\
\hline $58-861$ & date1.5 & $\mathrm{XVI}$ & 2.84 & {$[0.7-68.9]$} & 17.008 & 8.341 & & 0.066 & 0.030 \\
\hline $58-861$ & subproc2 & $\mathrm{XVIII}$ & 2.20 & {$[23.2-84.5]$} & 9.369 & 8.932 & & 0.028 & 0.057 \\
\hline
\end{tabular}

Data were obtained from a Populus nigra full-sib family (POP5) grown in two sites in Italy: Cavallermaggiore (CV) and Viterbo (VT). Selected traits related to bud set phenology (onset-of-stage traits: date2.5 and date1.5; duration traits: subproc1 and subproc2) were considered. For each QTL, the parental map, the linkage groups (LG), the logarithm of the odds (LOD), the $95 \%$ confidence interval (CI) in $\mathrm{CM}$, the genetic effect and the percentage of phenotypic variance explained (PVE) at CV and VT, are shown. $P$-values indicate significant site effect: ${ }^{*}, P \leq 0.05 ;{ }^{* *}, P \leq 0.01 ;{ }^{* * *}, P \leq 0.001$. PVE values $\geq 0.1$ are underlined.

of the parental genotype 'Poli' and three other P. nigra genotypes [30], allowed the calculation of the number of SNPs in each interval for 'Poli' and among the four $P$. nigra genotypes (Table 6).

QTL analyses cannot identify specific genes responsible for the phenotypic variation, but the integration of genomic data with the knowledge of gene function or expression allowed identifying promising CGs linked to bud set. Literature searches about phenology, coupled with the search of GenBank database, allowed finding a total of 997 genes reported to be involved in bud set. Among them, 774 sequences were located on the P. trichocarpa genome assembly v2 (corresponding to $1.9 \%$ of all $P$. trichocarpa genes), 722 were identified by Ruttink et al. [31], and 52 from other sources (Additional file 5: Table S3). Sixty seven expressional CGs from Ruttink et al. [31] and six from the other sources were within the seven QTL regions analyzed, corresponding to $2.2 \%$ of all genes contained in these intervals (Table 6 and
Additional file 5: Table S3). The latter set of six CGs were: one photoreception factor gene, Phytochrome $A$ (PhyA, GI: 2664188); three transcription factor genes for signal transduction, Constans2-like (Co-L2, GI: 831441), FAR-RED elongated hypocotyl 1 protein (FHY1.2), and PhyA signal transduction factor (PAT1-LGXVI); two circadian clock factor genes, circadian clock coupling factor (ZGT1like, GI:14210078 and ZGT2like, GI:14210078). Since these six candidates did not come from expressional evidence, a search in the available expressed sequence tag (EST) database (PopulusDB, GenBank and others) was conducted in order to find evidence of expression. All the six gene sequences showed significant hits vs. ESTs belonging to a mixed tissue preparation of Populus leaf, bud and stem, which could be referred to as phenology-related tissues. In the $P$. nigra mapping population, a single marker $t$-test (KruskalWallis) between phenotypic data of subproc1 and SNP polymorphism used to map PhyA indicated that this 


\section{P. nigra '58-861', maternal map}

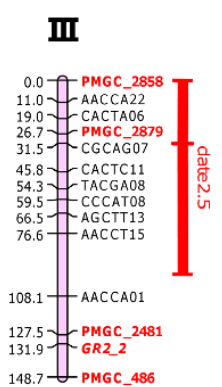

\section{VII}

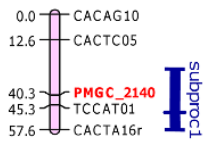

\section{$\mathbf{X}$}

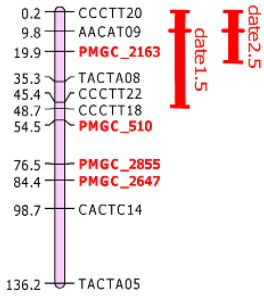

XVIII

\section{XIII}

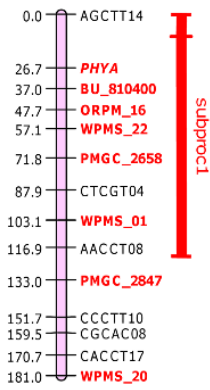

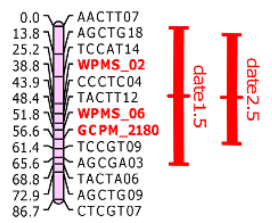

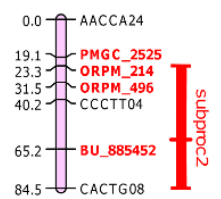

\section{P. nigra 'Poli', paternal map}

\section{I}

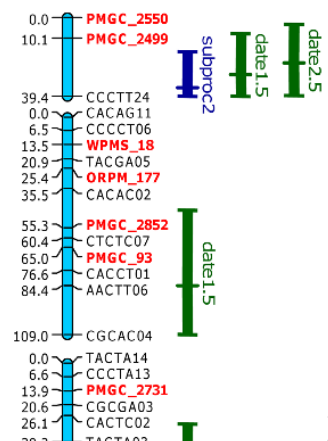

\section{IV}

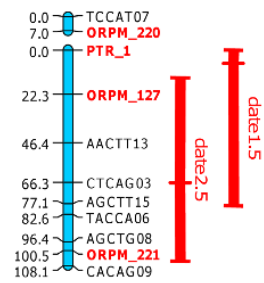

VI

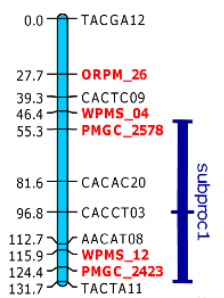

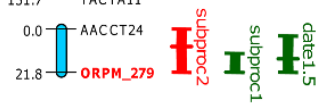

\section{XI}

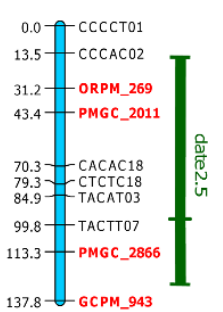

XIII

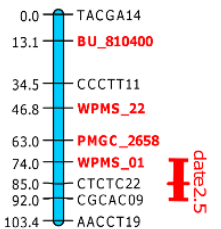

XVII

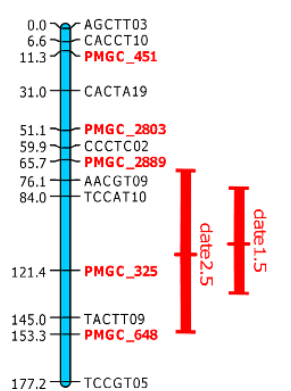

XIX

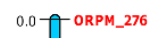

13.2 - AACGT03

20.1 \# 27.6 ORPTC23

27.6 \# ORPM_206
37.5 PMGC_2702

61.6 TACCA05

74.1 - $_{\text {CACTG07 }}$

0.0 AACATO4

${ }_{21.0}^{12.4} \amalg_{\text {CACCTA } 16}$

Figure 5 Quantitative trait loci (QTL) for bud set. Data were obtained from a Populus nigra full-sib family (POP5) grown in two sites in Italy: Cavallermaggiore (CV) and Viterbo (VT). Selected traits related to bud set phenology (onset-of-stage traits: date2.5 and date1.5; duration traits: subproc1 and subproc2) were considered. Roman numerals over the linkage groups (LGs) correspond to the P. trichocarpa chromosomes. LGs of maternal map (genotype '58-861') are in pink and LGs of paternal map (genotype 'Poli') are in blue. The length of the LG bars is proportional to the map distance in centiMorgan (CM). Numbers on the left of each LG indicate the marker position in $\mathrm{CM}$. Amplified Fragment Length Polymorphism (AFLP) markers are in black and Simple Sequence Repeats (SSRS) are in red and in bold. QTL are represented on the right side of the LGs by lines that indicate the $95 \%$ confidence interval. LOD peaks are marked by a short horizontal tick. Red lines denote QTL with a positive genetic effect in CV and VT. Green lines denote QTL with a negative genetic effect in CV and VT. Blue lines denote QTL with an opposite effect between $\mathrm{CV}$ and $\mathrm{VT}$. 
Table 5 Phenotypic variance explained by quantitative trait loci (QTL).

\begin{tabular}{lllllll}
\hline Trait & \multicolumn{2}{l}{ Number of QTL } & \multicolumn{3}{l}{ Total PVE (\%) } \\
\cline { 3 - 7 } & & & $\mathbf{5 8 - 8 6 1}$ & Poli \\
\cline { 2 - 7 } & $\mathbf{5 8 - 8 6 1}$ & Poli & CV & VT & CV & VT \\
\hline date2.5 & 3 & 5 & $\mathbf{1 4 . 9}$ & $\mathbf{2 2 . 3}$ & 30.5 & $\mathbf{2 4 . 7}$ \\
date1.5 & 2 & 5 & 10.4 & 14.3 & $\mathbf{4 0 . 1}$ & 20.5 \\
subproc1 & 2 & 4 & 10.7 & 9.5 & 20.6 & 14.5 \\
subproc2 & 1 & 2 & 2.8 & 5.7 & 23.0 & 0.2 \\
\hline
\end{tabular}

Total percentage of phenotypic variance (\%) explained (PVE) by the QTL per trait and per site for the two Populus nigra parents 'Poli' and '58-861'.

Maximum values per genotype and site are in bold.

SNP was not responsible for the effect of subproc1 QTL (data not shown). Furthermore, gene models were investigated closest to the logarithm of the odds (LOD) peak of selected QTL, considering $\pm 10 \mathrm{kbp}$ from the LOD peak position [32]. When no gene was found, the region was extended to $\pm 30 \mathrm{kbp}$ to find at least one gene per LOD peak. Eighteen gene models corresponding to these search criteria were found and listed in Additional file 6: Table S4. Some of these genes were functionally involved in regulation of transcription (putative transcription factors $M Y B 6, B N Q 1, b H L H)$, intracellular signal transduction (DC1 domain-containing protein), photomorphogenesis (CULLIN4) and UV light sensitivity (UVI4). The latter gene is also present in the list of expressional CGs found by Ruttink et al. [31]. Other genes close to LOD peaks were related to developmental process (CRINKLY4 RELATED, RABA4D), response to stress and/or hormones (AMK2, CCR4-NOT, ACR8) and others encoded structural constituent of ribosome (Additional file 6: Table S4). The EST database search revealed that 16 out of 18 gene models are putatively expressed. Among them, 13 models showed significant hits matching to EST libraries belonging to tissues related to phenology (i.e. bud, flower, apical shoot).

Given the data collected in terms of QTL co-localization, expression and literature reports, we came up with a set of most promising CGs for bud set traits composed of six functional candidates, 13 gene models and 67 expressional candidates.

\section{Discussion}

Unravelling bud set process and $\mathrm{G} \times \mathrm{E}$ interaction

Populus is an ideal model tree to study bud set because of its indeterminate shoot growth. Another factor worthy of consideration is that POP5 parental genotypes

Table 6 Selected quantitative trait loci (QTL) regions associated with bud set in Populus nigra.

\begin{tabular}{|c|c|c|c|c|c|c|c|c|c|c|c|c|c|}
\hline \multirow[t]{2}{*}{$\begin{array}{l}\text { Parent - } \\
\text { LG }\end{array}$} & \multirow[t]{2}{*}{ Traits } & \multirow[t]{2}{*}{ Flanking SSRs } & \multicolumn{2}{|c|}{$\begin{array}{l}\text { Overlap QTL } \\
\text { interval length }\end{array}$} & \multicolumn{2}{|c|}{$\begin{array}{l}\text { Position on } P . \\
\text { trichocarpa v2 } \\
\text { (kbp) }\end{array}$} & \multicolumn{3}{|c|}{$\begin{array}{l}\text { Genes and SNPs within } \\
\text { QTL interval }\end{array}$} & \multicolumn{2}{|c|}{$\begin{array}{l}722 \text { CGs from } \\
\text { Ruttink et al } \\
\text { [31] }\end{array}$} & \multicolumn{2}{|c|}{$\begin{array}{l}\text { CGs from } \\
\text { other sources }\end{array}$} \\
\hline & & & $\mathrm{cM}$ & Kbp & Start & End & Genes & $\begin{array}{l}\text { Poli } \\
\text { SNPs }\end{array}$ & $\begin{array}{l}\text { intrasp. } \\
\text { SNPs* }\end{array}$ & $\begin{array}{l}\text { all } \\
\text { LG }\end{array}$ & $\begin{array}{l}\text { within } \\
\text { QTL }\end{array}$ & $\begin{array}{l}\text { all } \\
\text { LG }\end{array}$ & $\begin{array}{l}\text { within } \\
\text { QTL }\end{array}$ \\
\hline \multirow[t]{3}{*}{ Poli - la } & date2.5 & $\begin{array}{l}\text { PMGC_2550- } \\
\text { PMGC_2499 }\end{array}$ & 22.12 & 1663.095 & 4828.200 & 6491.295 & 217 & 2967 & 14482 & 81 & 2 & 4 & 0 \\
\hline & date1.5 & & & & & & & & & & & & \\
\hline & subproc2 & & & & & & & & & & & & \\
\hline \multirow[t]{3}{*}{ Poli - IV } & date 2.5 & _PTR01-ORPM_221 & 64.2 & 7780.103 & 8083.898 & 15864.000 & 470 & 29159 & 88907 & 39 & 6 & 4 & 2 \\
\hline & date1.5 & & & & & & & & & & & & \\
\hline & date1.5 & & & & & & & & & & & & \\
\hline Poli - XIII & date 2.5 & $\begin{array}{l}\text { PMGC_2658- } \\
\text { WPMS_1 }\end{array}$ & 20.1 & 5524.000 & 6787.986 & 12312.018 & 322 & 17536 & 57215 & 42 & 5 & 1 & 0 \\
\hline \multirow[t]{2}{*}{ Poli - XVII } & date2.5 & $\begin{array}{l}\text { PMGC_2889- } \\
\text { PMGC_325 }\end{array}$ & 52.8 & 6159.403 & 8295.993 & 14455.396 & 445 & 23391 & 99316 & 21 & 7 & 2 & 1 \\
\hline & date1.5 & & & & & & & & & & & & \\
\hline \multirow[t]{2}{*}{$\begin{array}{l}58-861- \\
x\end{array}$} & date2.5 & $\begin{array}{l}\text { PMGC_2163- } \\
\text { PMGC_510 }\end{array}$ & 25 & 2839.533 & 3827.925 & 6667.458 & 125 & 11418 & 33742 & 46 & 2 & 4 & 0 \\
\hline & date1.5 & & & & & & & & & & & & \\
\hline $\begin{array}{l}58-861- \\
\text { XIII } \\
\end{array}$ & subproc1 & $\begin{array}{l}\text { WPMS_02- } \\
\text { GCPM_2180 }\end{array}$ & 120.9 & 10565.891 & 0.001 & 10565.891 & 954 & 30973 & 100689 & 42 & 29 & 1 & 1 \\
\hline \multirow[t]{2}{*}{$\begin{array}{l}58-861- \\
X V I\end{array}$} & date2.5 & $\begin{array}{l}\text { WPMS_02- } \\
\text { GCPM_2180 }\end{array}$ & 34.89 & 8956.860 & 0.001 & 8956.861 & 990 & 27957 & 94980 & 31 & 20 & 2 & 2 \\
\hline & date1.5 & & & & & & & & & & & & \\
\hline
\end{tabular}

QTL intervals were projected on the physical genome sequence by anchored markers (flanking SSRs). The length of the QTL intervals in centiMorgan (cM) and in Kilobase pairs $(\mathrm{Kbp})$ is given together with the number of gene models, single nucleotide polymorphisms (SNPs) for the male parent 'Poli' and SNPs between 'Poli' and three other P. nigra genotypes (71077-308, BEN3, and BDG) [30]. The table also reports the number of candidate genes (CGs) for bud development from Ruttink et al. [31] and other sources (literature and GenBank) on linkage groups (LG) containing QTL and within the QTL interval.

* SNPs among four P. nigra genotypes (Poli, 71077-308, BEN3, and BDG). 
originated from contrasting environments. These two advantages render powerful the exploration of the $G \times$ $E$ interaction patterns and phenotypic plasticity that are mostly uncharacterized for phenology traits. Recently, a new bud set scoring system in Populus spp. has led to the dissection of the bud set process into different stages and durations to estimate their relative contribution to the accomplishment of this phenological process [9]. Based on this new tool, the phenotypic plasticity and the $\mathrm{G} \times \mathrm{E}$ interaction was fully investigated in a $P$. nigra $F_{1}$ full-sib family using a multi-environment approach. The transition from shoot to bud structure (date1.5) was selected as the very critical determinant of bud set at both sites by PCA analysis. The selection of phenotypic descriptors characterizing key steps of bud set process allows to improve the estimation of genetic variation expressed at these different steps and the detection of more robust genomic regions involved in the phenological process. High phenotypic and genetic correlations between stage traits, consistent to those observed in P. nigra natural population [9], pointed out bud set as a cascade process, during which one phase could be indicative of the whole process. Genetic correlations between the two subprocesses vary in magnitude and sign from one environment to another. Indeed, in the past it was recognized that genetic correlations change across environments [33].

In the present study, the timing of stages and duration traits showed different levels of $\mathrm{H}^{2}$. This contrast could be explained simultaneously by different levels of expressed genetic variation and different levels of residual variation. Stage traits were characterized by a significant genotypic effect and a high heritability value, but the influence of the residual factors, either environmental conditions or precision of measure, augmented from date 2.5 to date 0.5 . The increase of the importance of environmental factor from date 2.5 to date 0.5 is contrary to the one observed by Rohde et al. [9] in hybrid poplars, but similar to the one observed in P. nigra natural populations studied in the same paper. A major genetic control of the last part of the process (date1, the only scored stage) was also found in a $F_{2}$ hybrid poplar pedigree by Howe et al. [34]. Similar results were also found by Li et al. [35] in interspecific poplar hybrids in two successive years. This major $\mathrm{H}^{2}$ may be explained by the use of interspecific hybrids that could increase the genetic variance and heritability estimation for these traits [34]. Nevertheless, heritability estimates have often been shown to be specific to the population and environment [36,37].

The total duration of the bud set process for POP5 was conserved at the two sites, but the time spent in each subprocess depended on the site. However, in both cases subproc 2 was longer than subproc1. Interestingly, as exhibited by phenotypic correlations we observed that the later genotypes for date 2.5 hastened subproc2, which could be an important strategy to avoid frost injury.

According to the concept of critical night length, where photoperiod is responsible for the onset of bud set process across environments and years [38], POP5 family reached date 2.5 at about the same effective night length at both sites. Importantly, ANOVA analysis for date2.5 showed a non-significant contribution of the environment effect and, on the opposite, a significant G $\times$ E effect (up to $19 \%$ of the phenotypic variability explained). This indicates that genotypes react differently to different environments. Data showed always a highly significant contribution of the $G \times E$ interaction in the phenotypic variation of all the stages, with a decreasing trend observed during the process. Rohde et al. [14] demonstrated that different locations differentially influenced the timing of growth cessation and the duration of bud formation in identical poplar genotypes, suggesting that high temperatures render the meristem less sensitive to growth-arresting photoperiodic signals. Moreover, Kalcsits et al. [11] showed that night temperature has a greater influence than day temperature in poplar. In the present study, the growth cessation of the plastic genotypes started earlier at the site with the lower minimum overnight temperature. Total duration of the bud set process for plastic genotypes was hastened in VT where lower temperatures were experienced during bud set. The site VT was globally warmer than $\mathrm{CV}$ with higher temperatures prevailing during the time until growth cessation, but the fall of temperatures recorded in VT during a limited number of nights was like a short treatment in an usually warmer site. Few recent studies showed that temperature can modify the timing of photoperiod controlling phenological events in deciduous woody plants $[11,13,39]$. The relative contribution of the $\mathrm{G} \times \mathrm{E}$ interaction on the phenotypic variation observed on date1 was perfectly comparable with the results of Luquez et al. [5] in P. tremula in two sites. In our $P$. nigra family the magnitude of $\mathrm{G} \times \mathrm{E}$ interaction partially increased from subproc1 to subproc2. The latter is a developmental period for which the genotypes of the analyzed family tended to respond differently to the various environments.

Distribution of genotype relative ecovalences showed that only few genotypes strongly contributed to the overall $\mathrm{G} \times \mathrm{E}$ interaction for date2.5. More than important rank changes, these genotypes revealed differences in the scale of response to environmental changes. This is the case for ' $58-861$ ', one of the earliest genotype for the onset of growth cessation (date2.5) at both sites but sensitive to cold temperatures. This could be an important survival strategy for trees to adjust their short-term response to temperature in a changing climate. 
Increasing rank change effect responsible for the $\mathrm{G} \times \mathrm{E}$ interaction was observed during the bud set process. Non-significant Spearman coefficients indicated random changes in genotype ranking for duration traits. Consequently, a major influence of environmental conditions on the variation of these traits was observed.

\section{Genomic regions containing QTL for bud set}

The QTL detected in this study explain a small proportion of the phenotypic variance $(\leq 10 \%)$, which is likely overestimated due to the relatively small progeny size [15]. However, several studies on global gene expression demonstrated the complex gene networks involved in bud formation, with large sets of genes temporally regulated during each phase of the process $[31,40,41]$. Therefore, one can expect a complex genetic control of bud formation by many genes with minor effect on the phenotype. Similar results were also described by Jermstad et al. [42] for spring bud flush in Douglas-fir. In forest trees, biological and technical constraints make difficult to manage wide progeny sizes, thus limiting the complete genome coverage with high resolution genetic maps. This negatively affects the detection of QTL with major effect, if present within uncovered genome regions, and reduces possibility to detect QTL with minor effect. The number of QTL identified also depends on the importance of genetic factors for the trait. This is in agreement with our observations, with more QTL identified for the onset-of-stage traits that showed medium to high $\mathrm{H}^{2}$ than for the duration traits.

The co-localization of most QTL for stages and subproc2 was in agreement with their high genetic correlation, relating to the physiological relationship between these traits. This could be due to the pleiotropic effect of a single gene affecting the traits or the physical linkage and/or linkage disequilibrium between two loci influencing the traits [43]. Negative genetic correlations indicate antagonistic effects of the loci on the traits. When stages QTL co-localized with the subproc2 QTL, they had opposite genetic effect.

Seven QTL on 'Poli' map and one on '58-861' map have significantly different effects between the two environments, underlying the significant $G \times E$ interaction. Phenotypic data indicated that genotype '58-861' was highly plastic, while 'Poli' encountered difficulties in adapting to the CV site. This suggests that the expression of alleles inherited from the 'Poli' parent is more dependent on the environment than the expression of alleles inherited from '58-861' parent.

Regardless of the slight changes in the genetic maps and the addition of a second site (VT), the QTL with high PVE were identified as in Rohde et al. [9], who analyzed the same mapping family but with less individuals. When the framework map was compared to that described by Gaudet et al. [29] and then used by Rohde et al. [9], the addition of new $F_{1}$ individuals has led to the mapping of new framework markers and to the splitting of some LGs. However, QTL were detected on LG-III, LG-VI and LG-XIII, which belong to the six robust regions selected by Rohde et al. [9]. Previously, QTL for bud set were identified in another pedigree of $P$. trichocarpa $\times$ P. deltoides on LG-III, VI and X [24]. These three LGs have also been detected in Rohde et al. [9] and in the current study. The genes PhyB2, LHY1 and $L H Y 2$, of which SNP polymorphism explain part of the phenotypic variation of bud set in $P$. tremula $[44,45]$, were not within the common QTL intervals across several Populus mapping pedigrees [9,24]. QTL regions recurrently identified in different pedigrees and environments are most likely robust genomic regions controlling the variation of the traits.

\section{Identifying positional candidate genes}

QTL mapping is an early step in identifying genes underlying trait variation [43]. The availability of the $P$. trichocarpa genome sequence adds a new dimension to QTL mapping, allowing to investigate genes within QTL intervals and map CGs in silico. Deep analysis of the most robust QTL regions allowed to highlight 13 gene models, 67 bud set-related expressional CGs and six functional CGs (PhyA, Co-L2, FHY1.2, PAT1, ZGT1like and ZGT2like).

The functional CGs are involved in light signaling pathway. In particular, Co- $L 2$, that belongs to the CONSTANS gene family, was found to be regulated by photoperiod and involved in growth cessation in Norway spruce [46] and Populus [47,48]. PAT1, FHY1.2, ZGT1like and ZGT2like are also involved in the regulation of PhyA signaling [49-51], which could affect the quantitative variation of bud set. This regulation mechanism could explain why PhyA was not directly responsible for the phenotypic variation of this trait (Kruskal-Wallis single marker $t$-test), even if it is well known to play a key role in growth cessation [52].

Another interesting CG is the $U V-B$ light insensitive 4 (UVI4), which is close to a peak of QTL LOD and also belongs to the expressional CGs found by Ruttink et al. [31]. UVI4 is responsive to UV-B light and its expression level decreased with the cessation of cell division in Arabidopsis thaliana [53]. In Populus, UVI4 gene was also found to be down-regulated during bud formation and cambial dormancy [31].

Among the hundred gene models annotated within our large QTL intervals, we investigated those close to peaks of LOD. The identified CGs that are then supported by in silico evidences of expression in phenologyrelated tissues, mainly respond to light and cold as the functional CGs within QTL intervals. Therefore, they 
could participate to environmental adaptation by the plasticity of their expression, which is in agreement with the phenotypic data.

\section{Conclusions}

The present work improves our understanding of the complex genetic architecture of bud set in poplar and of the considerable effect of $\mathrm{G} \times \mathrm{E}$ interaction in this process. QTL for bud set were identified and the projection of the most robust QTL on the P. trichocarpa genome, associated to previous gene expression studies, allowed the identification of CGs underlying the QTL. Furthermore, by investigating the physiological dynamics of bud set, we were able to confirm that the onset of growth cessation was triggered by night length, and the effect of environmental factors increased during the process. Additionally, a low number of plastic genotypes was responsible for the observed $\mathrm{G} \times \mathrm{E}$ interaction, with some of them being sensitive to temperature for the onset of growth cessation.

The recent development of the draft genome sequencing projects of $P$. nigra (Morgante \& Zaina, personal communication), as well as the whole-genome SNP annotation, and the high throughput SNP genotyping platform (Faivre-Rampant \& Zaina, personal communication) will be valuable tools allowing the scanning of allelic variation in CGs and analysis of natural populations by association mapping to determine the alleles associated with bud set traits. While some progress has been made in mapping bud set QTL, the elucidation of the underlying molecular mechanisms remains a bottleneck. Therefore, using expression QTL (eQTL) analysis will help to identify genes and gene networks associated to bud phenology and underlying traits involved in growth. This study opens up stimulating perspectives for molecular breeding aimed at increasing forest adaptation and productivity in a rapidly changing environment.

\section{Methods}

\section{Plant material}

A full-sib family of P. nigra (POP5) was used to score phenological characters and map QTL. The QTL mapping pedigree, already used in a previous genetic mapping study [29], consisted of 162 genotypes and derived from an intraspecific controlled cross between genotype '58-861' (female) from Val Cenischia (northern Italy; $45^{\circ}$ $09^{\prime} \mathrm{N}, 07^{\circ} 01^{\prime} \mathrm{E}$ ) and genotype 'Poli' (male) from Policoro (southern Italy; $40^{\circ} 09^{\prime} \mathrm{N}, 16^{\circ} 41^{\prime} \mathrm{E}$ ). The parents originate from contrasting environments and have highly divergent phenotypes [54].

\section{Experimental sites}

The study was conducted at two sites in northern $(\mathrm{CV}$, $\left.44^{\circ} 42^{\prime} \mathrm{N}, 07^{\circ} 41^{\prime} \mathrm{E}\right)$ and central Italy $\left(\mathrm{VT}, 42^{\circ} 25^{\prime} \mathrm{N}, 12^{\circ}\right.$ $\left.05^{\prime} \mathrm{E}\right)$ at an elevation of $285 \mathrm{~m}$ and $310 \mathrm{~m}$ above sea level, respectively. A third experimental plantation including seven randomly collected genotypes of POP5 and the two parents, was established in 2008 in northern Italy (SAV, $\left.44^{\circ} 36^{\prime} \mathrm{N}, 07^{\circ} 37^{\prime} \mathrm{E}\right)$. The soil is alluvial with sandy loam texture in CV and SAV, and sandy silt in VT. Annual precipitation and temperature averages of the years of study were $603 \mathrm{~mm}$ and $11.5^{\circ} \mathrm{C}(\mathrm{CV})$, $1125 \mathrm{~mm}$ and $14.2^{\circ} \mathrm{C}(\mathrm{VT})$, and $968 \mathrm{~mm}$ and $12.2^{\circ} \mathrm{C}$ (SAV). During the period of measurements (August, $1^{\text {st }}$ to October, $\left.31^{\text {st }}\right)$, rainfall in VT was lower than in CV and SAV (152.2 $\mathrm{mm}$ vs. $313.4 \mathrm{~mm}$ vs. $195.6 \mathrm{~mm}$ ), while the average daily minimum temperature was higher in VT $\left(13.4^{\circ} \mathrm{C}\right)$ as compared to $\mathrm{CV}$ and $\operatorname{SAV}\left(11.7^{\circ} \mathrm{C}\right)$ (Additional file 7: Figure S3). CNL, using sunrise and sunset times retrieved from the United States Naval Observatory http://aa.usno.navy.mil/, was calculated from the July, $1^{\text {st }}$ as a starting date. The same date was used for the calculation of $\mathrm{CMT}_{10}$. In this case, the temperature value below $10^{\circ} \mathrm{C}$ was subtracted to 10 , giving to lower temperatures a larger contribution to the parameter.

\section{Experimental design}

Three experimental plantations were established in April 2003 (CV) and April 2008 (VT and SAV) from hardwood cuttings $(25 \mathrm{~cm}$ long) planted at a distance of $2 \times$ $0.75 \mathrm{~m}$. The SAV experiment was used to reinforce the observations of phenotypic plasticity of the parents and POP5 genotypes. The field trials were established using a completely randomized block design with six blocks in $\mathrm{CV}$ and SAV and five blocks in VT. One ramet per genotype and parent was randomly assigned to each block. A double border row using clonal material of the same species was planted around the experimental plantations to reduce border effects. The sites were regularly irrigated and treated with pesticides as necessary throughout the growing season. Trees were coppiced at the end of the second growing season (February 2005) in CV and the first growing season (February 2009) in VT and SAV. The re-sprouts were thinned to a single stem.

\section{Phenotypic data collection \\ Bud set}

Phenological measurements were taken in autumn 2005 in CV and data were collected every two days from September 9 (DOY 252) to October 13 (DOY 286). In VT, bud set was scored in autumn 2008 and data were collected every three days, from September 15 (DOY 259) to October 20 (DOY 294). In SAV bud set was scored every ten days in 2009, from August 18 (DOY 230) to October 7 (DOY 280). All trees showing abnormal apical behavior biasing the natural phenological process were excluded from further measurements. The timing 
of six of the seven discrete phenological stages (from the active growth (date 3 ) to the end of bud maturation (date0.5)) were assessed by visual inspection as described in Rohde et al. [9] with a slight modification to the protocol as illustrated in Figure 6. Since date0 and date0.5 differ only in the color of the bud and were therefore difficult to be accurately measured, the former has been excluded in the current study. Data were smoothed using a local polynomial regression of degree 2 [55], with the different dates of observation as predictors, to estimate stages that had not been observed in the field because of the speed of the phenological process $\left(R^{2}\right.$ ranging from 0.964 to 0.999$)$. From the fitted curve, discrete values for DOY were retrieved for all stages from 3 to 0.5 , respecting the range of observed stages. Complementary traits such as duration of different stages and the length of the subprocess to complete bud formation (subproc1) and bud maturation (subproc2) were indirectly estimated (Figure 6). This new scoring system allows the measurement of all phenotypic aspects of growth cessation and bud set. The dataset from CV was statistically re-analyzed (data modified from Rohde et al. [9]) to enlarge the number of genotypes to be used for $\mathrm{G} \times \mathrm{E}$ analyses and the evaluation of phenotypic plasticity in the five discrete phenological stages. Bud set was recorded on 148 genotypes at $\mathrm{CV}$ and 154 genotypes at VT, with at least three replicates. The different number of genotypes was attributed to mortality.

\section{Growth}

Annual growth, expressed as the total stem height $(\mathrm{cm})$ and circumference $(\mathrm{mm})$, was measured at the end of the growing season (January 2006 at CV and December 2008 at VT). Stem height was measured with an accuracy of one $\mathrm{cm}$ using an extendable aluminum pole. Stem circumference was measured at $1 \mathrm{~m}$ above ground level to the nearest mm using a tape. These measurements were used as covariates to assess their influence on the phenotypic variation of the bud set process.

\section{Statistical analyses}

Data were analyzed using SAS software (SAS Institute, Cary, NC). Analyses of variance within and between sites, broad-sense heritability estimation at individual and genotypic level $\left(\mathrm{H}_{\text {ind }}{ }^{2}, \mathrm{H}_{\text {gen }}{ }^{2}\right)$ and Pearson correlations among traits were calculated as described in Dillen et al. [56]. The estimation of variance components was obtained using the restricted maximum likelihood (REML) procedure. Genetic correlations between traits, for each site, were calculated using $r_{g}=\sigma_{G(x y)} /\left[\sigma_{G(x)}^{2} \times\right.$ $\left.\sigma_{G(y)}^{2}\right]^{1 / 2}$, where $\sigma_{G(x)}^{2}$ is the genetic variance component for trait $x, \sigma_{G(y)}^{2}$ is the genetic variance component for trait $y$, and $\sigma_{G(x y)}$ is the genetic covariance between $x$ and $y$ [57]. The genetic covariance $\sigma_{G(x y)}$ was calculated according to the formula $\sigma_{G(x y)}=\left[\left(\sigma_{G(x+y)}\right)^{-\sigma^{2}}{ }_{G(x)^{-}}\right.$ $\left.\sigma_{G(y)}^{2}\right) / 2$ ] [34]. The variance of genetic correlation was calculated using $\sigma^{2}\left(r_{g}\right)=\left(1-r_{g}{ }^{2}\right)^{2} / n_{c}$ [58], where $n_{c}$ is the number of genotypes used to calculate the covariance component, and standard deviation as $S D=\left[\sigma^{2}\left(r_{g}\right)\right]^{1 / 2}$.

The $\mathrm{G} \times \mathrm{E}$ interaction, including site and year effects, was investigated in the current study. When the analysis of variance showed significant $\mathrm{G} \times \mathrm{E}$ interaction $(P \leq$ $0.05)$, the change in ranking of genotypes was evaluated by the Spearman rank coefficient $(\rho)$ on genotypic means. In order to dissect the $G \times E$ interaction and to understand genotype contribution to this source of phenotypic variance, the Wricke's relative ecovalence at genotypic level ( $\left.W_{i}^{r}\right)$ was used as a measure of the phenotypic plasticity of each genotype between environments [59].

Multivariate analyses using PCA were conducted on individual tree basis at each site to select traits that

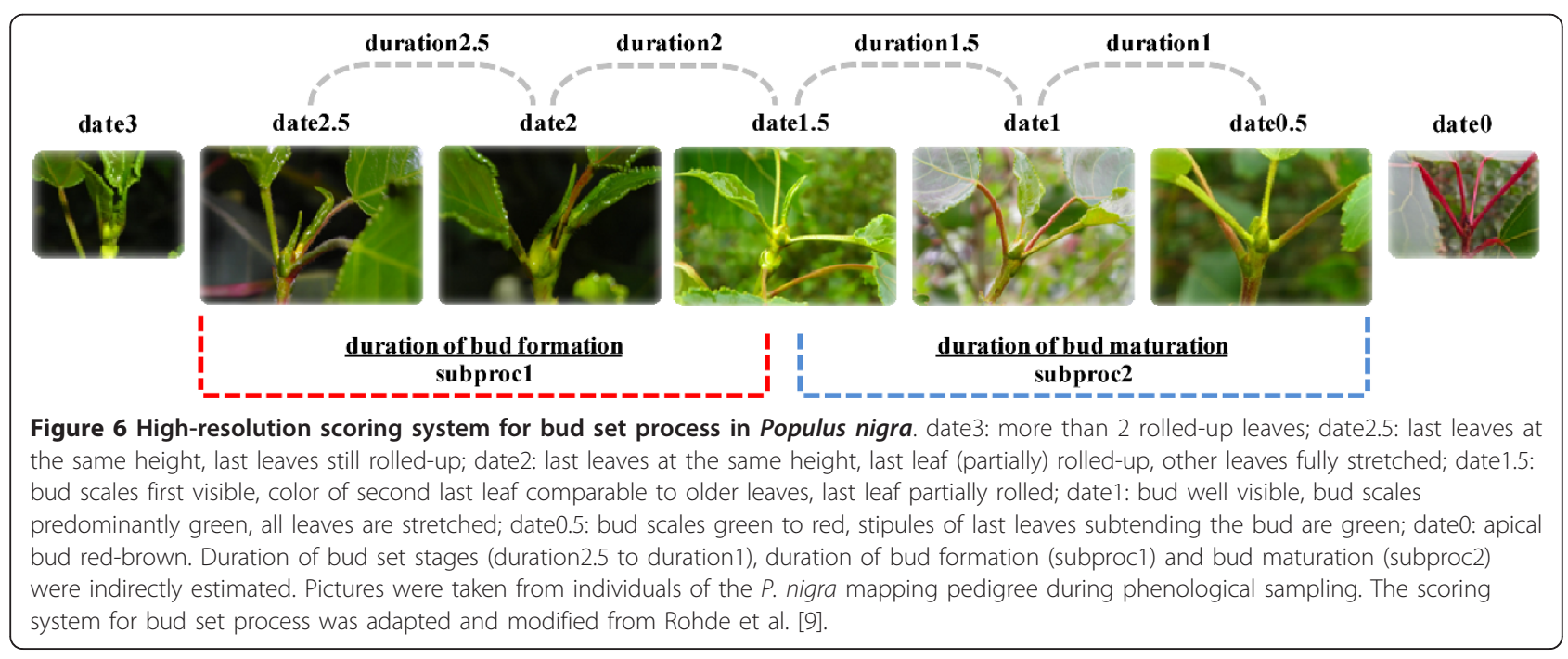


account for most of the variance in the observed phenological process before QTL analysis.

\section{QTL analyses}

QTL analyses were performed on selected traits (date2.5, date1.5, subproc1 and subproc2 expressed as CNL), which resulted after PCA as the most discriminative in terms of phenotypic variation. Analyses were carried out as described in Rae et al. [60] and in Rohde et al. [9]. The framework maps of the pedigree, described in Gaudet et al. [29], were improved by addition of 62 $F_{1}$ progenies to obtain a total of 154 individuals for QTL analysis. Data were processed with MultiQTL software http://www.multiqtl.com/ and the multiple environment approach was used to increase the accuracy of the estimated QTL position and effect $[56,60]$. The QTL presented in this study had a chromosome-wise statistical significance level of 0.05 and a bootstrap analysis with 1,000 data permutations was carried out to estimate the 95\% confidence interval of the QTL. The different effect of the QTL between the two sites was tested according to Rae et al. [60].

\section{QTL projections}

QTL were projected on the reference genome sequence of $P$. trichocarpa, using anchored markers. For each QTL, the SSRs nearest to the interval extremities and with known position on $P$. trichocarpa genome were used to calculate the relationship between the genetic and the physical distance [61] to obtain the physical coordinates of the QTL interval on the P. trichocarpa genome sequence. When two or more QTL co-located on the same genomic region, a unique overlap QTL interval was considered and a deep annotation of its sequence was done in terms of genes and SNP markers. The gene report was based on the U.S. Department of Energy Joint Genome Institute (JGI) v2.2 gene annotation of the $P$. trichocarpa genome assembly v2. The SNP report was based on the high-throughput resequencing of four P. nigra genotypes (Poli, 71077-308, BEN3, and BDG), which provided a genome-wide SNP detection, displayed through the IGA gbrowse tool [30].

\section{Candidate gene selection}

A bibliographical review was conducted to identify genes or gene models putatively associated with phenology $[6,9,52]$ in Populus. Keywords such as phenology, bud set, flowering time pathway, circadian-clock genes and photoperiod-related genes were used for a web-based search in PubMed and GenBank of the National Center for Biotechnology Information (NCBI) http://www.ncbi. nlm.nih.gov/. A key source of CGs was represented by Simpson \& Dean [62] and Ruttink et al. [31]. Then, the genes identified from the resulting literature collection were queried in the $P$. trichocarpa genome browser (JGI), assembly v2. When the query belonged to a different genus than Populus, a TBLASTX search was used; otherwise a BLASTN search was applied. The LG and base pair (bp) location of each gene model producing a statistically significant alignment with the query sequence was compared to the QTL intervals previously projected on the genome. Annotated genes known to be involved in bud set or development (or family members of such genes) that fell within these intervals were considered to be positional CGs. Their functionality was confirmed by searching the $P$. trichocarpa ESTs database http://www.populus.db.umu.se/index.html[63] in order to have an additional support in the discovery of the most promising CGs.

\section{Additional material}

Additional file 1: Figure S1. (Portable Document Format file) Photoperiod progression in the two experimental sites in Italy: Cavallermaggiore (CV) and Viterbo (VT). (a) The yearly variation in photoperiod at the two sites situated at $44^{\circ} \mathrm{N}\left(\mathrm{CV}\right.$, red full lines) and $42^{\circ} \mathrm{N}$ (VT, black dotted lines), as well as for $35^{\circ} \mathrm{N}$ and $50^{\circ} \mathrm{N}$ of latitude. The gray lines correspond to the period of measurements of bud set process. (b) Cumulative night length (CNL) was calculated from July 1st in CV (red full lines) and VT (black dotted lines).

Additional file 2: Figure S2. (Portable Document Format file) Linear regression between growth and selected phenological traits. Data were obtained from a Populus nigra full-sib family (POP5) grown in two sites in Italy: Cavallermaggiore (CV) and Viterbo (VT).

Additional file 3: Table S1. (Portable Document Format file) Genetic variation in a Populus nigra full-sib family (POP5) grown in Cavallermaggiore (CV) in Italy. Parental values (i.e. female parent '58-861' mean \pm standard error (SE)), family values (i.e. population means \pm SE and level of significance differences between $F_{1}$ genotypes) and genetic parameters (i.e. coefficient of genetic $\left(\mathrm{CV}_{\mathrm{g}}\right)$ and residuals $\left(\mathrm{CV}_{\varepsilon}\right)$ variation and broad-sense heritability at individual $\left(\mathrm{H}_{\text {ind }}{ }^{2}\right)$ and genotypic $\left(\mathrm{H}_{\text {gen }}{ }^{2}\right)$ level \pm SE). The F-test between parents were not performed because of the absence of 'Poli' (see Materials and Methods).

Additional file 4: Table S2. (Portable Document Format file) Genetic variation in a Populus nigra full-sib family (POP5) grown in Viterbo (VT) in Italy. Parental values (i.e. female parent '58-861' and male parent 'Poli' means \pm standard error (SE) and level of significance difference between the two), family values (i.e. population means \pm SE and level of significance differences between $F_{1}$ genotypes) and genetic parameters (i.e. coefficient of genetic $\left(\mathrm{CV}_{\mathrm{g}}\right)$ and residuals $\left(\mathrm{CV}_{\varepsilon}\right)$ variation and broadsense heritability at individual $\left(\mathrm{H}_{\text {ind }}{ }^{2}\right)$ and genotypic $\left(\mathrm{H}_{\text {gen }}{ }^{2}\right)$ level $\pm \mathrm{SE}$ ). The significance level of the $F$-test between the two parents for each trait is indicated as: $n s$, non significant; ${ }^{*}, P \leq 0.05 ;{ }^{* *}, P \leq 0.01 ;{ }^{* * *}, P \leq$ 0.001 .

Additional file 5: Table S3. (Microsoft Excel file) List of candidate genes (CGs) from bibliography sources.

Additional file 6: Table S4. (Portable Document Format file) Gene models search relating to bud set. Gene models in Populus trichocarpa genome sequence closest to the logarithm of the odds (LOD) peak of selected quantitative trait loci (QTL) for bud set traits found in P. nigra. Gene models were searched in the sequence at $\pm 10 \mathrm{Kbp}$ around the position of LOD peak or $\pm 30 \mathrm{Kbp}$ to find at least one gene per LOD peak. LG, linkage group on which QTL were found. bp, base pairs.

Additional file 7: Figure S3. (Portable Document Format file) Meteorological characteristics of the three experimental sites taken into account for phenotypic plasticity. Data were obtained from nearby meteorological stations in the three experimental sites in Italy, 
Cavallermaggiore (CV), Viterbo (VT) and Savigliano (SAV), where the Populus nigra full-sib family (POP5) was studied.

\section{Acknowledgements}

The authors are grateful to Michele Baldasso for his help in the phenological measurements in 2005 and to the Company Alasia Franco Vivai for the management of CV and SAV plantation sites. This work was supported by grants from the European Union (QLK5-CT-2002-00953 POPYOMICS, FP7211868 NOVELTREE). AH is supported by the Brain Gain Program (Rientro dei cervelli) of the Italian Ministry of Education, University and Research (MIUR).

\section{Author details}

${ }^{1}$ Department for Innovation in Biological, Agro-food and Forest systems, University of Tuscia, Via S. Camillo de Lellis, Viterbo 01100, Italy. ${ }^{2}$ INRA, UR 0588, National Institute for Agricultural Research, Orléans 2 F-45075, France. ${ }^{3}$ Department of Agriculture and Environmental Sciences, University of Udine, Via delle Scienze, Udine 33100, Italy. ${ }^{4}$ Institute for Mediterranean Agriculture and Forest Systems, National Research Council, Via Madonna Alta, Perugia 06128, Italy. ${ }^{5}$ INRA, UMR 1137, INRA-Nancy University, Champenoux F-54280, France. ${ }^{6}$ Istituto di Genomica Applicata, Via J. Linussio 51, Udine 33100, Italy. ${ }^{7}$ Department of Agronomy, Forestry and Land use, Agricultural Research Council, Via del Caravita, Roma 00186, Italy.

\section{Authors' contributions}

FF and MS participated in the design and performance of the experiments, statistical analyses, data interpretation and writing of the paper; NM coperformed phenological experiments; MG carried out QTL data analyses; MG, GZ and MM performed candidate gene identification, and participated in writing of the paper; $\mathrm{AH}$ and $\mathrm{IB}$ participated in data analyses and interpretation, and writing of the paper. MS, CB and GSM conceived and supervised the study. All authors jointly interpreted the results, read and approved the final manuscript.

\section{Competing interests}

The authors have no business relationships that could be construed as a potential conflict of interest.

\section{Received: 21 October 2011 Accepted: 3 April 2012}

Published: 3 April 2012

\section{References}

1. Howe GT, Gardner G, Hackett WP, Furnier GR: Phytochrome control of short-day-induced bud set in black cottonwood. Physiol Plantarum 1996 97:95-103

2. Pauley SS, Perry TO: Ecotypic variation of the photoperiodic response in Populus. J Arnold Arboretum 1954, 35:167-188.

3. Neale DB, Ingvarsson PK: Population, quantitative and comparative genomics of adaptation in forest trees. Curr Opin Plant Biol 2008, 11:149-155.

4. Rohde A, Howe GT, Olsen JE, Moritz T, Van Montagu M, Junttila O, Boerjan W: Molecular aspects of bud dormancy in trees. In Molecular Biology of Woody Plants. Volume 1. Edited by: Jain SM, Minocha SC. Dordrecht, The Netherlands: Kluwer Academic Publishers; 2000:89-134.

5. Luquez V, Hall D, Albrectsen BR, Karlsson J, Ingvarsson P, Jansson S: Natural phenological variation in aspen (Populus tremula): the SwAsp collection. Tree Genet Genomes 2008, 4:279-292.

6. Ingvarsson PK, Garcia MV, Hall D, Luquez V, Jansson S: Clinal variation in phyB2, a candidate gene for day-length-induced growth cessation and bud set, across a latitudinal gradient in European aspen (Populus tremula). Genetics 2006, 172:1845-1853.

7. Hall D, Luquez V, Garcia VM, St Onge KR, Jansson S, Ingvarsson PK: Adaptive population differentiation in phenology across a latitudinal gradient in european aspen (Populus tremula, L.): a comparison of neutral markers, candidate genes and phenotypic traits. Evolution 2007, 61:2849-2860.

8. Aitken SN, Yeaman S, Holliday JA, Wang T, Curtis-McLane S: Adaptation, migration or extirpation: climate change outcomes for tree populations. Evol Appl 2008, 1:95-111.
9. Rohde A, Storme V, Jorge V, Gaudet M, Vitacolonna N, Fabbrini F, Ruttink T, Zaina G, Marron N, Dillen S, et al: Bud set in poplar - genetic dissection of a complex trait in natural and hybrid populations. New Phytol 2011, 189:106-121.

10. Howe GT, Hackett WP, Furnier GR, Klevorn RE: Photoperiodic responses of a northern and southern ecotype of black cottonwood. Physiol Plantarum 1995, 93:695-708.

11. Kalcsits L, Silim S, Tanino K: Warm temperature accelerates short photoperiod-induced growth cessation and dormancy induction in hybrid poplar (Populus $\times$ spp.). Trees 2009, 23:971-979.

12. Håbjørg A: Effects of photoperiod and temperature on growth and development of three latitudinal and three altitudinal populations of Betula pubescens Ehrh. Meld Nor Landbrukshøgsk 1972, 51:1-27.

13. Tanino KK, Kalcsits L, Silim S, Kendall E, Gray GR: Temperature-driven plasticity in growth cessation and dormancy development in deciduous woody plants: a working hypothesis suggesting how molecular and cellular function is affected by temperature during dormancy induction. Plant Mol Biol 2010, 73:49-65.

14. Rohde A, Bastien C, Boerjan W: Temperature signals contribute to the timing of photoperiodic growth cessation and bud set in poplar. Tree Physiol 2011, 31:472-482.

15. Howe GT, Aitken SN, Neale DB, Jermstad KD, Wheeler NC, Chen THH: From genotype to phenotype: unraveling the complexities of cold adaptation in forest trees. Can J Botany 2003, 81:1247-1266.

16. Johnsen $\varnothing$, Dæhlen OG, Østreng G, Skrøppa T: Daylength and temperature during seed production interactively affect adaptive performance of Picea abies progenies. New Phytol 2005, 168:589-596.

17. Johnsen $\varnothing$, Fossdal CG, Nagy N, Mølmann J, Dæhlen OG, Skrøppa T: Climatic adaptation in Picea abies progenies is affected by the temperature during zygotic embryogenesis and seed maturation. Plant Cell Environ 2005, 28:1090-1102.

18. Kvaalen $H$, Johnsen $\varnothing$ : Timing of bud set in Picea abies is regulated by a memory of temperature during zygotic and somatic embryogenesis. New Phytol 2008, 177:49-59.

19. Visser ME: Keeping up with a warming world; assessing the rate of adaptation to climate change. Proc $R$ Soc $B$ 2008, 275:649-659.

20. Kramer K, Leinonen I, Loustau D: The importance of phenology for the evaluation of impact of climate change on growth of boreal, temperate and Mediterranean forests ecosystems: an overview. Int J Biometeorol 2000, 44:67-75.

21. Chmielewski FM, Rötzer T: Response of tree phenology to climate change across Europe. Agr Forest Meteorol 2001, 108:101-112.

22. Primack RB, Miller-Rushing AJ: The role of botanical gardens in climate change research. New Phytol 2009, 182:303-331.

23. Nicotra AB, Atkin OK, Bonser SP, Davidson AM, Finnegan EJ, Mathesius U, Poot P, Purugganan MD, Richards CL, Valladares F, et al: Plant phenotypic plasticity in a changing climate. Trends Plant Sci 2010, 15:684-692.

24. Frewen BE, Chen THH, Howe GT, Davis J, Rohde A, Boerjan W, Bradshaw HD Jr: Quantitative trait loci and candidate gene mapping of bud set and bud flush in Populus. Genetics 2000, 154:837-845.

25. Gailing O, Vornam B, Leinemann L, Finkeldey R: Genetic and genomic approaches to assess adaptive genetic variation in plants: forest trees as a model. Physiol Plantarum 2009, 137:509-519.

26. Tuskan GA, DiFazio S, Jansson S, Bohlmann J, Grigoriev I, Hellsten U, Putnam N, Ralph S, Rombauts S, Salamov A, et al: The genome of black cottonwood, Populus trichocarpa (Torr. \& Gray). Science 2006, 313:1596-1604.

27. Chen THH, Howe GT, Bradshaw HD: Molecular genetic analysis of dormancy-related traits in poplars. Weed Sci 2002, 50:232-240.

28. Brunner A, Sheng X, Edwards J, Fujino T, Wang CT, DiFazio S: Regulation of shoot-system development in Populus. BMC Proc 2011, 5(Suppl 7):111.

29. Gaudet M, Jorge V, Paolucci I, Beritognolo I, Scarascia Mugnozza G, Sabatti M: Genetic linkage maps of Populus nigra L. including AFLPs, SSRs, SNPs, and sex trait. Tree Genet Genomes 2008, 4:25-36.

30. Giacomello S: Next-generation sequencing in Populus nigra: de novo assembly, genome-wide SNP map and comparative genomics analysis. PhD thesis University of Udine, Udine, Italy; 2011.

31. Ruttink T, Arend M, Morreel K, Storme V, Rombauts S, Fromm J, Bhalerao RP, Boerjan W, Rohde A: A molecular timetable for apical bud formation and dormancy induction in poplar. Plant Cell 2007, 19:2370-2390. 
32. Celton JM, Martinez S, Jammes MJ, Bechti A, Salvi S, Legave JM, Costes E: Deciphering the genetic determinism of bud phenology in apple progenies: a new insight into chilling and heat requirement effects on flowering dates and positional candidate genes. New Phytol 2011, 192:378-392.

33. Stearns $S$, de Jong G, Newman B: The effects of phenotypic plasticity on genetic correlations. Trends Ecol Evol 1991, 6:122-126.

34. Howe GT, Saruul P, Davis J, Chen THH: Quantitative genetics of bud phenology, frost damage, and winter survival in an $F_{2}$ family of hybrid poplars. Theor Appl Genet 2000, 101:632-642.

35. Li B, Howe GT, Wu R: Developmental factors responsible for heterosis in aspen hybrids (Populus tremuloides $\times$ P. tremula). Tree Physiol 1998, 18:29-36.

36. Souza VAB, Byrne DH, Taylor JF: Heritability, genetic and phenotypic correlations, and predicted selection response of quantitative traits in peach: II. An analysis of several fruit traits. J Am Soc Hort Sci 1998, 123:604-611.

37. Hendry AP, Kinnison MT, Heino M, Day T, Smith TB, Fitt G, Bergstrom CT, Oakeshott J, Jørgensen PS, Zalucki MP, et al: Evolutionary principles and their practical application. Evol App/ 2011, 4:159-183.

38. Nitsch JP: Growth responses of woody plants to photoperiodic stimuli. $P$ Am Soc Hortic Sci 1957, 70:512-525.

39. Mølmann JA, Asante DKA, Jensen JB, Krane MN, Ernstsen A, Junttila O, Olsen JE: Low night temperature and inhibition of gibberellin biosynthesis override phytochrome action and induce bud set and cold acclimation, but not dormancy in PHYA overexpressors and wild-type of hybrid aspen. Plant Cell Environ 2005, 28:1579-1588.

40. Ophir R, Pang X, Halaly T, Venkateswari J, Lavee S, Galbraith D, Or E: Geneexpression profiling of grape bud response to two alternative dormancy-release stimuli expose possible links between impaired mitochondrial activity, hypoxia, ethylene-ABA interplay and cell enlargement. Plant Mol Biol 2009, 71:403-423.

41. Kayal WE, Allen CCG, Ju CJT, Adams E, King-Jones S, Zaharia LI, Abrams SR Cooke JEK: Molecular events of apical bud formation in white spruce, Picea glauca. Plant Cell Environ 2011, 34:480-500.

42. Jermstad KD, Bassoni DL, Jech KS, Wheeler NC, Neale DB: Mapping of quantitative trait loci controlling adaptive traits in coastal Douglas-fir. I. Timing of vegetative bud flush. Theor Appl Genet 2001, 102:1142-1151.

43. Hausmann NJ, Juenger TE, Sen S, Stowe KA, Dawson TE, Simms EL: Quantitative trait loci affecting $\delta^{13} \mathrm{C}$ and response to differential water availability in Arabidopsis thaliana. Evolution 2005, 59:81-96.

44. Ingvarsson PK, Garcia MV, Luquez V, Hall D, Jansson S: Nucleotide polymorphism and phenotypic associations within and around the phytochrome B2 locus in European aspen (Populus tremula, Salicaceae). Genetics 2008, 178:2217-2226.

45. Ma XF, Hall D, St.Onge KR, Jansson S, Ingvarsson PK: Genetic differentiation, clinal variation and phenotypic associations with growth cessation across the Populus tremula photoperiodic pathway. Genetics 2010, 186:1033-1044.

46. Holefors A, Opseth L, Ree Rosnes AK, Ripel L, Snipen L, Fossdal CG, Olsen JE: Identification of PaCOL1 and PaCOL2, two CONSTANS-like genes showing decreased transcript levels preceding short day induced growth cessation in Norway spruce. Plant Physiol Bioch 2009, 47:105-115.

47. Yuceer C, Harkess RL, Land SB, Luthe DS: Structure and developmental regulation of CONSTANS-LIKE genes isolated from Populus deltoides. Plant Sci 2002, 163:615-625.

48. Böhlenius H, Huang T, Charbonnel-Campaa L, Brunner AM, Jansson S, Strauss $\mathrm{SH}$, Nilsson O: CO/FT regulatory module controls timing of flowering and seasonal growth cessation in trees. Science 2006, 312:1040-1043.

49. Torres-Galea P, Huang LF, Chua NH, Bolle C: The GRAS protein SCL13 is a positive regulator of phytochrome-dependent red light signaling, but can also modulate phytochrome A responses. Mol Genet Genomics 2006, 276:13-30.

50. Marrocco K, Zhou Y, Bury E, Dieterle M, Funk M, Genschik P, Krenz M, Stolpe T, Kretsch T: Functional analysis of EID1, an F-box protein involved in phytochrome A-dependent light signal transduction. Plant J 2006, 45:423-438.

51. Yang SW, Jang IC, Henriques R, Chua NH: FAR-RED ELONGATED HYPOCOTYL1 and FHY1-LIKE associate with the Arabidopsis transcription factors LAF1 and HFR1 to transmit phytochrome a signals for inhibition of hypocotyl elongation CW. Plant Cell 2009, 21:1341-1359.

52. Olsen JE: Light and temperature sensing and signaling in induction of bud dormancy in woody plants. Plant Mol Biol 2010, 73:37-47.

53. Hase $Y$, Trung $\mathrm{KH}$, Matsunaga $T$, Tanaka A: A mutation in the uvi4 gene promotes progression of endo-reduplication and confers increased tolerance towards ultraviolet B light. Plant J 2006, 46:317-326.

54. Regier N, Streb S, Cocozza C, Schaub M, Cherubini P, Zeeman SC, Frey B: Drought tolerance of two black poplar (Populus nigra L.) clones: contribution of carbohydrates and oxidative stress defence. Plant Cell Environ 2009, 32:1724-1736.

55. Cleveland WS, Grosse E, Shyu WM: Local regression models. In Statistical models in S. Edited by: Chambers JM, Hastie TJ. New York: Chapman and Hall; 1992:309-376.

56. Dillen SY, Storme V, Marron N, Bastien C, Neyrinck S, Steenackers M, Ceulemans R, Boerjan W: Genomic regions involved in productivity of two interspecific poplar families in Europe. 1. Stem height, circumference and volume. Tree Genet Genomes 2009, 5:147-164.

57. Burdon RD: Genetic correlation as a concept for studying genotypeenvironment interaction in forest tree breeding. Silvae Genet 1977, 26:168-175.

58. Visscher PM: On the sampling variance of intraclass correlations and genetic correlations. Genetics 1998, 149:1605-1614.

59. Wricke G: Über eine Methode zur Erfassung der ökologischen Streubreite in Feldversuchen. Z Pflanzenzüchtg 1962, 47:92-96.

60. Rae AM, Pinel MPC, Bastien C, Sabatti M, Street NR, Tucker J, Dixon C, Marron N, Dillen SY, Taylor G: QTL for yield in bioenergy Populus: identifying $\mathrm{G} \times \mathrm{E}$ interactions from growth at three contrasting sites. Tree Genet Genomes 2008, 4:97-112.

61. Ranjan P, Yin T, Zhang X, Kalluri UC, Yang X, Jawdy S, Tuskan GA: Bioinformatics-based identification of candidate genes from QTLs associated with cell wall traits in Populus. Bioenerg Res 2010, 3:172-182.

62. Simpson GG, Dean C: Arabidopsis, the Rosetta stone of flowering time? Science 2002, 296:285-289.

63. Sterky F, Bhalerao RR, Unneberg P, Segerman B, Nilsson P, Brunner AM, Charbonnel-Campaa L, Lindvall JJ, Tandre K, Strauss SH, et al: A Populus EST resource for plant functional genomics. P Natl Acad Sci USA 2004, 101:13951-13956.

doi:10.1186/1471-2229-12-47

Cite this article as: Fabbrini et al:: Phenotypic plasticity, QTL mapping and genomic characterization of bud set in black poplar. BMC Plant Biology 2012 12:47.

\section{Submit your next manuscript to BioMed Central and take full advantage of:}

- Convenient online submission

- Thorough peer review

- No space constraints or color figure charges

- Immediate publication on acceptance

- Inclusion in PubMed, CAS, Scopus and Google Scholar

- Research which is freely available for redistribution

Submit your manuscript at www.biomedcentral.com/submit
C Biomed Central 